\title{
Evidence-based gene models for structural and functional annotations of the oil palm genome
}

\author{
Kuang-Lim Chan ${ }^{1,2+} \mathbb{B}$, Tatiana V. Tatarinova ${ }^{3,4+}$, Rozana Rosli ${ }^{1,5}$, Nadzirah Amiruddin', Norazah Azizi ${ }^{1}$, \\ Mohd Amin Ab Halim ${ }^{1}$, Nik Shazana Nik Mohd Sanusi ${ }^{1}$, Nagappan Jayanthi ${ }^{1}$, Petr Ponomarenko ${ }^{4}$, Martin Triska ${ }^{6}$, \\ Victor Solovyev ${ }^{7}$, Mohd Firdaus-Raih², Ravigadevi Sambanthamurthi ${ }^{1}$, Denis Murphy ${ }^{5}$ and Eng-Ti Leslie Low ${ }^{1 *}$
}

\begin{abstract}
Background: Oil palm is an important source of edible oil. The importance of the crop, as well as its long breeding cycle (10-12 years) has led to the sequencing of its genome in 2013 to pave the way for genomics-guided breeding. Nevertheless, the first set of gene predictions, although useful, had many fragmented genes. Classification and characterization of genes associated with traits of interest, such as those for fatty acid biosynthesis and disease resistance, were also limited. Lipid-, especially fatty acid (FA)-related genes are of particular interest for the oil palm as they specify oil yields and quality. This paper presents the characterization of the oil palm genome using different gene prediction methods and comparative genomics analysis, identification of FA biosynthesis and disease resistance genes, and the development of an annotation database and bioinformatics tools.

Results: Using two independent gene-prediction pipelines, Fgenesh++ and Seqping, 26,059 oil palm genes with transcriptome and RefSeq support were identified from the oil palm genome. These coding regions of the genome have a characteristic broad distribution of $\mathrm{GC}_{3}$ (fraction of cytosine and guanine in the third position of a codon) with over half the $\mathrm{GC}_{3}$-rich genes $\left(\mathrm{GC}_{3} \geq 0.75286\right)$ being intronless. In comparison, only one-seventh of the oil palm genes identified are intronless. Using comparative genomics analysis, characterization of conserved domains and active sites, and expression analysis, 42 key genes involved in FA biosynthesis in oil palm were identified. For three of them, namely EgFABF, EgFABH and EgFAD3, segmental duplication events were detected. Our analysis also identified 210 candidate resistance genes in six classes, grouped by their protein domain structures.
\end{abstract}

Conclusions: We present an accurate and comprehensive annotation of the oil palm genome, focusing on analysis of important categories of genes ( $\mathrm{GC}_{3}$-rich and intronless), as well as those associated with important functions, such as FA biosynthesis and disease resistance. The study demonstrated the advantages of having an integrated approach to gene prediction and developed a computational framework for combining multiple genome annotations. These results, available in the oil palm annotation database (http://palmxplore.mpob.gov.my), will provide important resources for studies on the genomes of oil palm and related crops.

Reviewers: This article was reviewed by Alexander Kel, Igor Rogozin, and Vladimir A. Kuznetsov.

Keywords: Oil palm, Gene prediction, Seqping, Fatty acids, Intronless, Resistance genes

\footnotetext{
* Correspondence: lowengti@mpob.gov.my

${ }^{\dagger}$ Equal contributors

${ }^{1}$ Advanced Biotechnology and Breeding Centre, Malaysian Palm Oil Board,

No. 6, Persiaran Institusi, Bandar Baru Bangi, 43000 Kajang, Selangor, Malaysia

Full list of author information is available at the end of the article
} 


\section{Background}

Oil palm is in the genus Elaeis of family Arecaceae. The genus has two species - E. guineensis (African oil palm) and E. oleifera (American oil palm). There are three fruit forms of E. guineensis, mainly differing in their shell thickness dura (thick shell), tenera (thin shell) and pisifera (no shell). The African oil palm is by far the most productive oil crop [1] in the world, with estimated production in year 2015/ 2016 of 61.68 million tonnes, of which the Malaysian share was 19.50 million tonnes [2]. Palm oil constitutes $\sim 34.35 \%$ of the world's production of edible oils. Globally, palm oil is mainly produced from E. guineensis in the tenera fruit form. E. oleifera is not used commercially due to its low yield. However, it is more disease-resistant and can grow in areas where cultivating guineensis is not feasible, e.g., Central-Southern America. Even then, it is mainly planted as a backcross to guineensis (interspecific hybrid) to increase the yield. Nevertheless, it has economically valuable traits which plant breeders wish to introgress into guineensis, such as a more liquid oil with higher carotenoid and vitamin E contents, disease resistance and slow height increment [1].

The importance of oil palm has resulted in interest to sequence its transcriptomes and genome. Initial efforts were based on expressed sequence tags (ESTs) [3], but the technique, while useful for tagging expressed genes, only provided partial coverage of the coding regions and genome. Next, GeneThresher ${ }^{\text {ta }}$ technology was applied to selectively sequence hypomethylated regions of the genome [4]. The oil palm AVROS pisifera genome sequence was subsequently released in 2013 [5], and this facilitated completion of the draft oil palm dura genome [6]. With the genome sequence [5], coupled with genetic and homozygosity mapping via sequencing, the SHELL gene was identified [7]. This facilitated an efficient genetic test to distinguish between the dura, pisifera and tenera fruit forms. Subsequently, the VIRESCENS gene, which regulates the fruit exocarp color [8], and the MANTLED gene, which causes tissue culture abnormality [9], were also discovered. Accurate genome annotation was critical for the identification of these genes, and will be crucial for increasing oil palm productivity.

First gene prediction pipelines appeared in the 1990s. In 1997, mathematicians from Stanford developed the Genscan [10] software, followed by a steady stream of specially designed tools to navigate the complexity of various genomes. Combining multiple predictors led to the development of automated pipelines integrating various types of experimental evidence [11]. A major limitation shared by many approaches is their relatively poor performance in organisms with atypical distribution of nucleotides [12-15]. The $\mathrm{GC}_{3}$ content of the genes plays an important role, as $\mathrm{GC}_{3}$-rich genes in grasses can be better predicted by transcriptome-based rather than homology-based methods [16]. Accurate gene prediction is one of the most important challenges in computational biology, as the prediction quality affects all aspects of genomics analysis.

In our effort to overcome the lack of precision in many predictive models, we developed a computational framework to generate high quality gene annotations for oil palm. The framework uses a combination of the Seqping [17] pipeline developed at the Malaysian Palm Oil Board (MPOB), and the Fgenesh++ [18] pipeline by Softberry. Individual components of the framework were trained on known genes of plants closely related to the oil palm, such as the date palm, to identify the most suitable parameters for gene prediction. The best gene model for each locus was selected to establish a representative "high confidence" gene set. Genes associated with important agronomical traits, namely 42 fatty acid biosynthetic genes and 210 candidate resistance genes, were also identified. The gene information and annotations, made available in an oil palm annotation database, will be an important resource for breeding disease and stress resistant palms with enhanced productivity. This paper describes the identification and characterization of a "high confidence" set of 26,059 oil palm genes that have transcriptome and RefSeq support, and bioinformatics analysis of the genes, including comparative genomics analysis, and database and tool development.

\section{Methods \\ Datasets}

We used the E. guineensis P5-build of an AVROS pisifera palm from Singh et al. [5], which contained 40,360 genomic scaffolds (N50 length: 1,045,414 nt; longest length: 22,100,610 nt; and shortest length: $1992 \mathrm{nt})$. The E. guineensis mRNA dataset is a compilation of published transcriptomic sequences from Bourgis et al. [19], Tranbarger et al. [20], Shearman et al. [21, 22], and Singh et al. [7], as well as 24 tissue-specific RNA sequencing assemblies from MPOB submitted to GenBank in BioProject PRJNA201497 and PRJNA345530 (see Additional file 1), and oil palm expressed sequence tags downloaded from the nucleotide database in GenBank. This dataset was used as transcriptome evidence, and to train the Hidden Markov Model (HMM) for gene prediction.

\section{Fgenesh++ gene prediction}

Fgenesh++ (Find genes using Hidden Markov Models) $[18,23]$ is an automatic gene prediction pipeline, based on Fgenesh, a HMM-based ab initio gene prediction program [24]. We used oil palm genomic scaffolds to predict the initial gene set, applying the Fgenesh gene finder with generic parameters for monocots. From this set, we selected a subset of predicted genes that encode highly homologous proteins (using BLAST with 
E-value $<1.0 \mathrm{E}-10)$ to known plant proteins from the NCBI non-redundant (NR) database. We computed the optimized gene-finding parameters using this subset of predicted oil palm genes as the training set, and executed the Fgenesh++ pipeline to annotate the genes in the genomic scaffolds. The Fgenesh++ pipeline considered all available supporting data, such as the E. guineensis mRNA dataset and homologous protein sequences. NR plant, and specifically, palm transcripts were mapped to the oil palm genomic scaffolds, identifying a set of potential splice sites. Plant proteins were also mapped to the oil palm genomic scaffolds and high scoring matches were selected to generate protein-supported gene predictions. This ensured that only highly homologous proteins were used in gene identification.

Amino acid sequences from the predicted oil palm genes were then compared to the protein sequences from plant NR database using the 'bl2seq' routine, with the similarity considered significant if it had blast percent identity $\geq 50$, blast score $\geq 100$, coverage of predicted protein $\geq 80 \%$ and coverage of homologous protein $\geq 80 \%$. BLAST analysis of the predicted sequences was also carried out against the E. guineensis mRNA dataset, using an identity cutoff of $>90 \%$. Predictions that have both NR plant RefSeq and E. guineensis mRNA support were selected for further analysis.

\section{Seqping gene prediction}

Seqping [17], a customized gene prediction pipeline based on MAKER2 [25], was developed by MPOB. Full-length open reading frames (ORFs) were identified from the E. guineensis mRNA dataset described above, using the EMBOSS getorf program. ORFs between 500 and $5000 \mathrm{nt}$ were selected to minimize potential prediction errors. Using BLASTX [26] search, selected ORFs with E-values <1E-10 were considered significantly similar to the RefSeq plant protein sequences. ORFs with BLASTX support were clustered using BLASTClust and CD-HIT-EST [27], and subsequently filtered using the TIGR plant repeat database [28], GIRI Repbase [29], and Gypsy Database [30] to remove ORFs similar to retroelements. The resulting set of ORFs was used as the training set to develop HMMs for three modellers, GlimmerHMM [31, 32], AUGUSTUS [33] and SNAP [34] programs, which were subsequently used for gene predictions. Seqping uses MAKER2 [25] to combine predictions from the three modelers. All programs used the default parameters in Seqping. The predicted sequences were compared to the RefSeq [35] protein sequences and E. guineensis mRNA dataset by BLAST. Predictions that have NR plant RefSeq and $E$. guineensis mRNA support (E-value cutoff: $1 \mathrm{E}-10)$ were selected for further analysis.

\section{Integration of Fgenesh++ and Seqping gene predictions} To increase the accuracy of annotation, predictions independently made by the Seqping and Fgenesh++ pipelines were combined into a unified prediction set. All predicted amino acid sequences were compared to protein sequences in the NR database using BLAST (E-value cutoff: 1E-10). ORF predictions with $<300$ nucleotides were excluded. Predicted genes from both pipelines in the same strand were considered overlapping if the shared length was above the threshold fraction of the shorter gene length. A colocated group of genes on the same strand was considered to belong to the same locus if every gene in the group overlapped at least one other member of the same group (single linkage approach) at the selected overlap threshold. Different overlap thresholds, from $60 \%$ to $95 \%$ in $5 \%$ increments, were tested to determine the best threshold value, simultaneously maximizing the annotation accuracy and minimizing the number of single-isoform loci. Protein domains were predicted using PFAM-A [36, 37] (release 27.0) and PfamScan ver. 1.5. The coding sequences (CDSs) were also compared to NR plant sequences from RefSeq (release 67), using the phmmer function from the HMMER-3.0 package $[38,39]$. To find the representative gene model and determine its function for each locus, we selected the lowest Evalue gene model in each locus and the function of its RefSeq match. We excluded hits with E-values $>1 \mathrm{E}-10$, as well as proteins that contained words "predicted", "putative", "hypothetical", "unnamed", or "uncharacterized" in their descriptions, keeping only high-quality loci and their corresponding isoforms. Loci without the RefSeq match were discarded. The CDS in each locus with the best match to the RefSeq database of all plant species was selected as the best representative CDS for the locus. Gene Ontology (GO) annotations were assigned to the palm genes, using the best NCBI BLASTP hit to Oryza sativa sequences from the MSU rice database [40] at an E-value cutoff of 1E-10.

\section{Intronless genes}

Intronless genes (IG) were identified as mono-exonic genes containing full-length ORFs, as specified by the gene prediction pipeline. The same approach was applied to five other genomes: A. thaliana (TAIR10) [41], O. sativa (MSU 6.0) [40], S. bicolor (Phytozome 6.0), Z. mays (Phytozome) and Volvox carteri (Phytozome 8.0) [42]. Lists of non-redundant IG from all six genomes were obtained, and the oil palm IG were compared to them using BLASTP (E-value cutoff: 1E-5). The protein sequences of the IG were also mapped to all NCBI genes in the archaea, bacteria and eukaryote kingdoms using BLASTP with the same cutoff.

\section{Resistance (R) genes}

All curated plant resistance $(\mathrm{R})$ genes were downloaded from the database PRGdb 2.0 [43]. A local similarity 
search of known plant resistance genes and oil palm gene models was done using the BLASTP program with E-value $\leq 1 \mathrm{E}-5$. TMHMM2.0 [44] was used to find predicted transmembrane helices in the known $R$ genes, as well as in the oil palm candidate $R$ genes, and these results were used to classify the $\mathrm{R}$ genes. Domain structures of the known and oil palm candidate $R$ genes were identified using InterProScan. All the domains found were used to classify the candidate $\mathrm{R}$ genes according to the PRGdb classification. To be considered an R gene, the gene had to contain all the domains found in known $\mathrm{R}$ genes of its class. Our selection was validated on the published "resistance" gene motifs [45-49] and each class further validated via multiple sequence alignment and phylogenetic tree, using the ClustalW [50] and MEGA6 [51] programs, respectively. The same procedure was used to identify $\mathrm{R}$ genes in A. thaliana [41], O. sativa [40], $S$. bicolor, $Z$. mays and $V$. carteri genomes. Distribution of coiled-coil (CC) - nucleotide binding site (NBS) leucine-rich repeat (LRR) or CNL class $\mathrm{R}$ genes across 16 chromosomes of the EG5 genome build [5] was conducted to identify physical clustering. A cluster of $\mathrm{R}$ genes is defined as two CNL genes located less than $200 \mathrm{~kb}$ apart, with no more than eight non NBS-LRR genes in between them [52, 53].

\section{Fatty acid (FA) biosynthesis genes}

A. thaliana, O. sativa, Z. mays, Glycine max and Ricinus communis amino acid sequences corresponding to $11 \mathrm{FA}$ biosynthesis genes were obtained from KEGG [54]. The corresponding amino acid sequences for another three genes, oleoyl-phosphatidylcholine desaturase [FAD2], linoleoyl-phosphatidylcholine desaturase [FAD3], acylacyl carrier protein (ACP) thioesterase [FATB], were obtained from journals [55-58]. These sequences were compared to oil palm gene models using Exonerate [59] with the "protein2dna" alignment model parameter. The oil palm gene models were annotated using BLASTX against the RefSeq database. Conserved domains of these genes were identified using InterProScan [60] against the HMMPfam database $[36,61]$. Corresponding protein sequences of candidate oil palm FA biosynthesis genes and FA biosynthesis genes from other organisms were aligned using the ClustalW program. The catalytic residues and conserved motifs of the amino acid sequences of the corresponding candidate FA biosynthesis genes were identified from literature [62-73]. Sequences of identified FA genes having more than one copy were extracted with additional flanking regions of $10 \mathrm{Mb}$ upstream and downstream to check for genome duplication using the PROmer [74] software with default parameters.

\section{Expression analysis}

To estimate the expression of FA biosynthesis genes, two Illumina HiSeq 2000 libraries each of mesocarp and kernel samples in NCBI BioProject PRJNA245226 [5], were read-mapped to the P5-build of the oil palm genome using the Tuxedo suite [75, 76]. Fragments Per Kilobase of transcript per Million mapped fragments (FPKM) was calculated, with the expression of each gene the mean of measures from two biological replicates. Expressions of genes in root, leaf, leaf apex and flower from BioProject PRJNA201497 were determined by mapping two Roche 454 sequencing transcriptome data for each tissue using the same method.

\section{Comparative genomics}

To identify the orthologs of FA biosynthesis and R genes in oil palm sequences, OrthoMCL2.0 [77] was used with its default parameters to construct orthologous groups across three sets of gene models: E. guineensis, A. thaliana and $Z$. mays. The corresponding protein sequences of these genes were confirmed with BLASTP [26] searches against the NCBI NR database with default parameters. Protein members of the cluster sequences were aligned by two methods, Muscle [78] and MAFFT [79] version 7. Protein domain sequences were identified using Pfam [37], InterPro [80], ScanProsite [81] and NCBI CDD [82]. To get an overview of the relationships between selected orthologous genes, phylogenetic trees were constructed using MEGA6 [51] and MAFFT [83]. All programs were used with their default settings.

\section{Results and discussion}

\section{Gene models}

A variety of tools has been developed for prediction and annotation of protein-coding genes, such as Fgenesh++ [18], MAKER-P [84], Gramene [85], GeneMark [86, 87], and Ensembl [88]. Plant genomes (such as A. thaliana, Medicago truncatula, O. sativa, E. guineensis, Fragaria vesca and others) are generally annotated using a combination of evidence-based gene models and ab initio predictions [6, 89-92]. The first version of the oil palm genome [5], which is from the AVROS pisifera palm, was published in 2013 with assembled sequences representing $\sim 83 \%$ of the 1.8 Gb-long genome. Using this assembly, we predicted gene models by combining output from the two pipelines, Fgenesh++ and Seqping [17].

Previous studies of five ab initio pipelines, Fgenesh++, GeneMark.hmm, GENSCAN, GlimmerR and Grail, to evaluate gene prediction precision showed that Fgenesh++ produced the most accurate maize genome annotations [23]. Fgenesh++ is a common tool for eukaryotic genome annotation, due to its superior ability to predict gene structure [93-96]. In the oil palm genome, Fgenesh++ predicted 117,832 whole and partial-length gene models of at least 
500 nt long. A total 27,915 Fgenesh++ gene models had significant similarities to the E. guineensis mRNA dataset and RefSeq proteins (Fig. 1).

To improve the coverage and accuracy of gene prediction, and to minimize prediction bias, Seqping, which is based on the MAKER2 pipeline [25], was also used. Seqping is an automated pipeline that generates species-specific HMMs for predicting genes in a newly sequenced organism. It was previously validated using the $A$. thaliana and $O$. sativa genomes [17], where the pipeline was able to predict at least 95\% of the Benchmarking Universal SingleCopy Orthologs's (BUSCO) [97] plantae dataset (BUSCO provides quantitative measures for the assessment of gene prediction sets based on evolutionarily-informed expectations of gene content from near-universal single-copy orthologs [97]). Seqping demonstrated the highest accuracy compared to three HMM-based programs (MAKER2, GlimmerHMM, and AUGUSTUS) with the default or available HMMs [17]. The pipeline was used to train the oil palm specific HMMs. This was done by identifying 7747 putative full-length CDS from the transcriptome data. Using this set, the oil palm-specific HMMs for GlimmerHMM [31, 32], AUGUSTUS [33], and SNAP [34] were

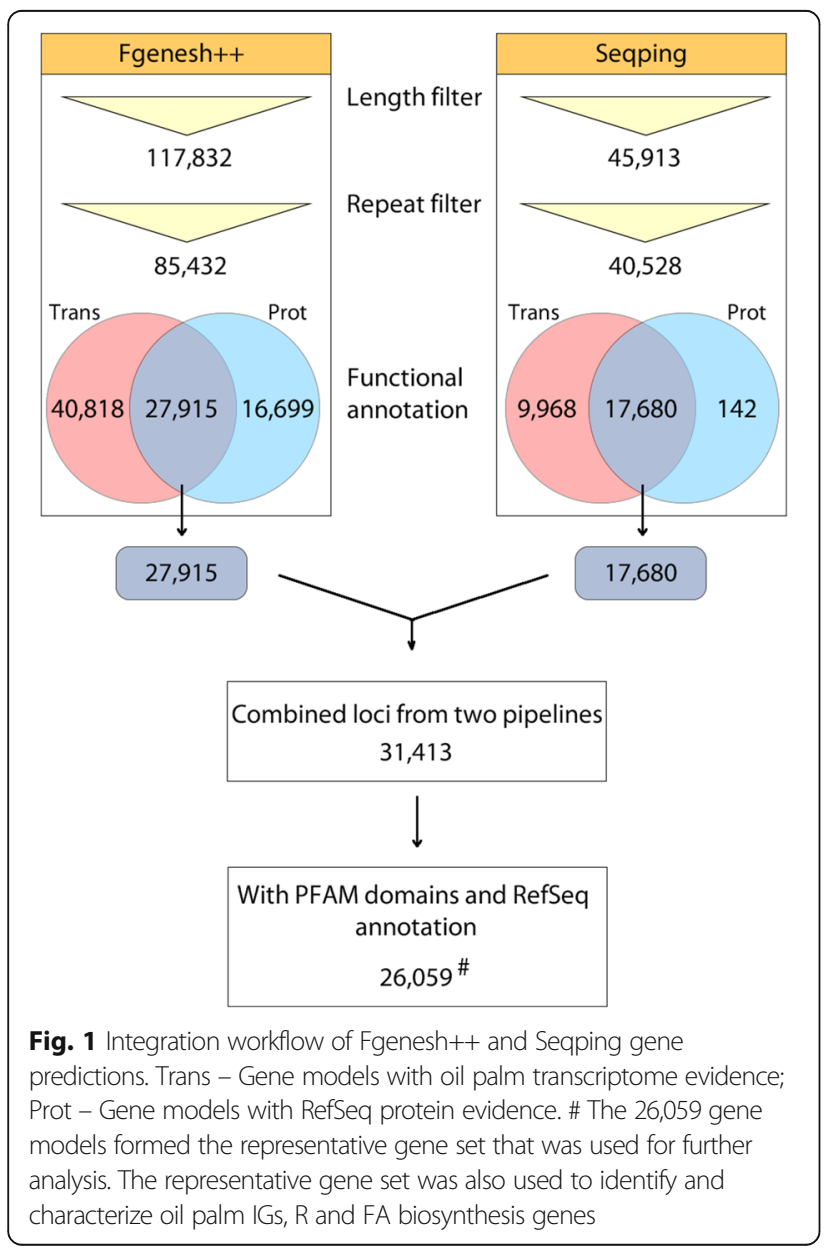

trained. These HMMs were used in MAKER2 to predict oil palm genes. The initial prediction identified 45,913 gene models that were repeat-filtered. A total 17,680 Seqping gene models had significant similarities to the $E$. guineensis mRNA dataset and RefSeq proteins (Fig. 1).

The 27,915 and 17,680 gene models from Fgenesh++ and Seqping respectively were then combined. Since the ratio of single-gene model to multi-gene model loci increased more rapidly above the $85 \%$ overlap between two loci (Fig. 2 and Additional file 2: Table S1), we set this value as the overlap threshold. Gene models that had an overlap $\geq 85 \%$ were grouped into a locus. This threshold allowed us to minimize false positives in merging loci, while maximizing true positives in joining gene models into one locus. The gene models in a single locus must also be predicted from the same strand. Examples of these overlaps are shown in Additional file 3: Figures S1a and S1b. 31,413 combined loci (Additional file 2: Table S1) in 2915 scaffolds were obtained, of which 26,087 contained gene models with PFAM domains and RefSeq annotations. Of them, 13,228 contained one ORF, 12,111 two, and 748 three or more. For every locus, the CDS with the best match to plant proteins from the RefSeq database was selected as its best representative CDS.

The genomic scaffolds containing predicted genes were screened by MegaBLAST search against the RefSeq Representative Genome Database (E-value cutoff: 0; hits to E. guineensis excluded). If the best BLAST hits were represented by bacterial or plastid plant genomes, the scaffolds were marked as potential contaminants. Forty three potential contaminant scaffolds were identified and checked manually. The scaffolds were also compared to the oleifera genome, RNA-seq data and the latest Pisifera genome builds that MPOB uses internally. Scaffolds with no support in all three levels were removed from the final dataset, 24 scaffolds containing 28 loci. The remaining representative CDS for 26,059 genomic loci (the "high quality" dataset) are supported by the oil palm transcriptome and RefSeq data. The sequences and annotations of the 26,059 genes are available in the PalmXplore system (http://palmx plore.mpob.gov.my). PalmXplore is an integrated database system that allows researchers to search, retrieve and browse oil palm gene information and associated functional annotations using a series of search engines. The system is also linked to Blast tools and the oil palm palm genome browser (MYPalmViewer; http://gbrowse.mpob.gov.my/). Screenshots of the system are available in Additional file 4.

Gene structure analysis of the high quality dataset showed that $14 \%$ were intronless and $16 \%$ contained only two exons. 395 genes had more than 20 exons. Further analyses on these genes using BLASTX (E-value cutoff: 1E-5) to determine their identity and exon numbers, showed that 366 had alignment coverage above $90 \%$ with the RefSeq [35] genes. The number increased to 384 genes 


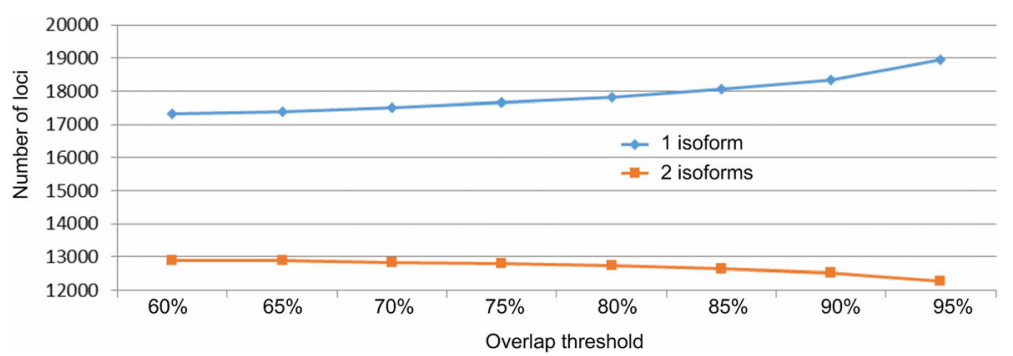

Fig. 2 Overlap thresholds using the rate of increase of single-isoform loci. Based on the widening divergence at 85\%, the level was selected as the overlap threshold

when the cutoff was reduced to at least $80 \%$ coverage. The two oil palm genes with the largest exon number $(57$ exons) were p5.00_sc00063_p0008 and p5.00_sc00076_ p0105. Detailed examination of gene p5.00_sc00063_ p0008 showed it is similar to serine/threonine-protein kinase TOR from Musa acuminate, Vitis vinifera, Citrus sinensis and Theobroma cacao, which also have 57 exons. Interestingly, the oil palm translation activator GCN1 (p5.00_sc00076_p0105) was similar to the genes in Phoenix dactylifera, $V$. vinifera, $O$. sativa and $M$. acuminate with 60 exons. The distributions of exons per gene and CDS lengths are shown in Fig. 3a and b respectively. Evolutionary conservation of gene structure was previously described for several species and gene families

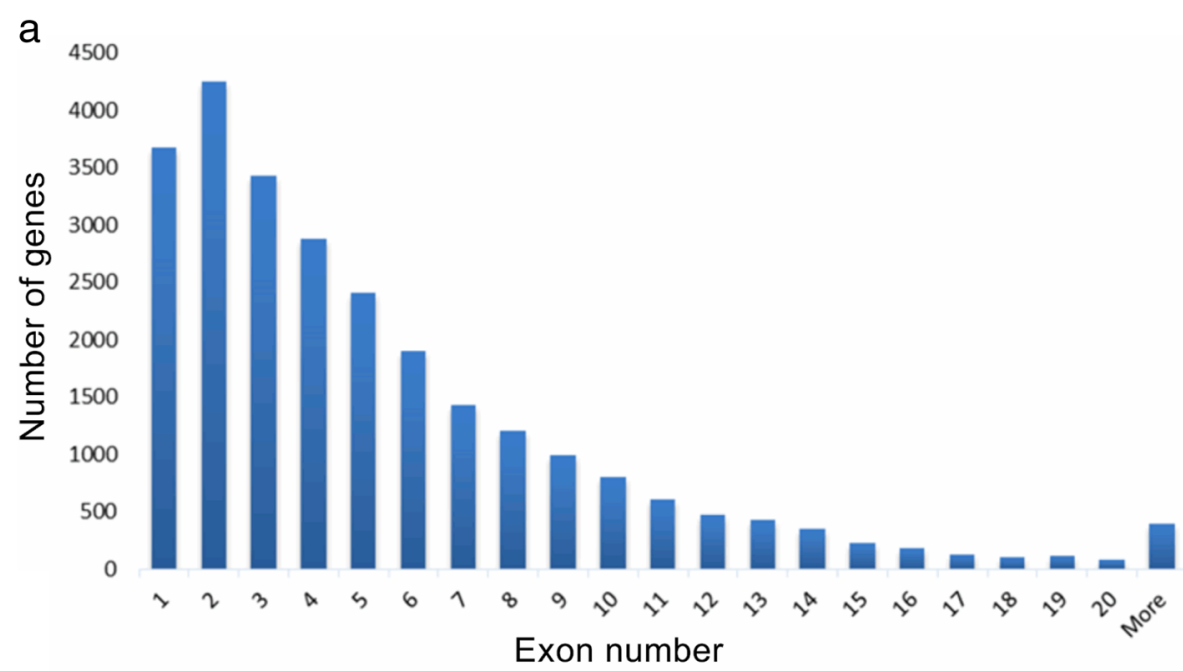

b

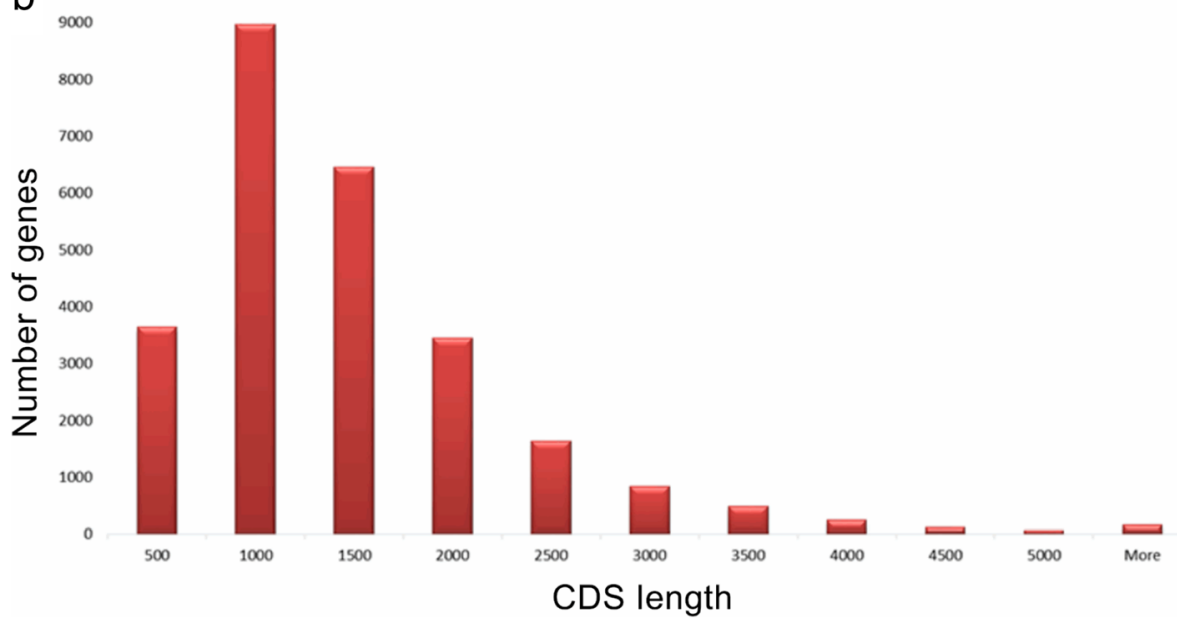

Fig. 3 Distribution of oil palm gene models. a Number of genes vs. number of exons per gene $\mathbf{b}$ Number of genes vs lengths of CDS 
$[98,99]$. For example, it was estimated that in mouse and human, $86 \%$ of the orthologous gene pairs have the same number of coding exons [100].

BUSCO analysis [97] of the high quality dataset showed $90.44 \%$ of the 429 eukaryotic BUSCO profiles available. By comparing to 1440 embryophyta BUSCO profiles (Additional file 2: Table S2), $85.76 \%$ of the BUSCO genes were found in the predicted gene models, including $81.25 \%$ as complete BUSCO genes, thus quantifying the completeness of the oil palm genome annotation. By comparison, the first set of gene prediction by Singh et al. [5] in 2013 had matches to only $60.35 \%$ of the embryophyta BUSCO profiles, with $41.60 \%$ as complete BUSCO genes, indicating a big improvement in the latest gene models. Also, for each gene in the current and 2013 annotation, we compared the best match to the plant RefSeq database using the NCBI BLASTP program. The new pisifera annotation has higher identity to the RefSeq proteins than the old one. The high quality dataset also had better predictions than the 36,105 gene models identified in the dura genome [6]. BUSCO analysis (Additional file 2: Table S2) shows that the pisifera annotations contain 53\% more complete (1170 vs. 765 ), $55 \%$ less fragmented (65 vs. 145), and $61 \%$ less missing (205 vs. 530) BUSCO profiles than those from dura. The average number of exons in dura is 4.3 , and in pisifera 5.4. The predicted mean CDS length of dura (900 nt) is also shorter than pisifera (1232 nt).

\section{Nucleotide composition of oil palm genes}

One important characteristic of a genome is the frequency of guanine and cytosine occurring in the third codon position, $\mathrm{GC}_{3}$, which is defined as $\frac{C_{3}+G_{3}}{(L / 3)}$, where $L$ is the length of the coding region, $C_{3}$ the number of cytosines, and $G_{3}$ the number of guanines in the third position of codons in the coding region [16]. Two types of $\mathrm{GC}_{3}$ distribution have been described - unimodal and bimodal $[16,101,102]$. Genes with high and low $\mathrm{GC}_{3}$ peaks have distinct functional properties [102]. $\mathrm{GC}_{3}$-rich genes provide more targets for methylation, exhibit more variable expression, more frequently possess upstream TATA boxes and are predominant in stress responsive genes. Different gene prediction programs have variable bias to different classes of genes, but $\mathrm{GC}_{3}$-rich genes are reported to be especially hard to predict accurately [103]. The distribution of $\mathrm{GC}_{3}$ is bimodal in grasses and warm-blooded vertebrates, and unimodal in other species sequenced to date [104].

The distribution of $\mathrm{GC}_{3}$ in oil palm is unimodal with a long tail towards high values of $\mathrm{GC}_{3}$. Figure 4a shows the distribution of $\mathrm{GC}_{3}$ in the high quality dataset. We ranked all genes by their $\mathrm{GC}_{3}$ contents and designated the top $10 \%$ (2606 ORFs) as $\mathrm{GC}_{3}$-rich $\left(\mathrm{GC}_{3} \geq 0.75286\right)$ and the bottom $10 \%$ as $\mathrm{GC}_{3}$-poor $\left(\mathrm{GC}_{3} \leq 0.373239\right)$. Two of the remarkable features that distinguish $\mathrm{GC}_{3}$-rich and -poor genes are the gradients of $\mathrm{GC}_{3}$ and $\mathrm{CG}_{3}$-skew, defined as $C G_{3}^{\text {skew }}=\frac{C_{3}-G_{3}}{C_{3}+G_{3}}$, where $C_{3}$ and $G_{3}$ are the frequencies of cytosines or guanines in the third position of the codon, correspondingly. An increase in the $C G_{3}^{\text {skew }}$ from $5^{\prime}$ to $3^{\prime}$ has been linked to transcriptional efficiency and methylation status $[16,102,105]$ of the $\mathrm{GC}_{3}$-rich genes. Figure $4 \mathrm{c}$ and $\mathrm{d}$ show the positional gradients of nucleotide composition. The $\mathrm{GC}_{3}$ content of $\mathrm{GC}_{3}$-rich genes increases from the $5^{\prime}$ to $3^{\prime}$ end of the gene, but decreases in $\mathrm{GC}_{3}$-poor genes. Despite the relatively small number of $\mathrm{GC}_{3}$-rich genes in the oil palm genome, there are characteristic patterns of positional gradients (Fig. $4 \mathrm{c}$ and $\mathrm{d}$ ) near the predicted start of translation, as also found in other wellannotated genomes [16].

The dinucleotide CG relative abundance (a.k.a. "genomic signature") is defined as $\rho_{C G}=\frac{f_{C G}}{f_{C} f_{G}}$, where $f_{x}$ is the frequency of a (di)nucleotide $x$ [106]. Similar to grasses, and other previously analyzed plant and animal species $[16,102]$, the oil palm genome signature differs for $\mathrm{GC}_{3}$-rich and $\mathrm{GC}_{3}$-poor genes (Fig. $4 \mathrm{~b}$ ). The $\mathrm{GC}_{3}$-rich genes are enriched and the $\mathrm{GC}_{3}$-poor genes depleted in the number of $\mathrm{CpG}$ sites that are potential targets for methylation. Gene ontology analysis shows that many of the $\mathrm{GC}_{3}$-rich genes are stress-related, while many of the $\mathrm{GC}_{3}$-poor genes have housekeeping functions (see GO annotation in Additional file 2: Table $\mathrm{S} 3$ ). The depletion of $\mathrm{CpGs}$ in $\mathrm{GC}_{3}$-poor genes is consistent with their broad constitutive expression [16]. This analysis is based on the classification described above where the $\mathrm{GC}_{3}$-rich genes were defined as the top $10 \%$ genes with the highest $\mathrm{GC}_{3}$ content, and the $\mathrm{GC}_{3}$-poor genes the bottom $10 \%$ of all genes with the lowest $\mathrm{GC}_{3}$ content. If there is no relationship between nucleotide composition and GO categories, the distribution of genes in the GO categories would be the same for all the genes in the entire genome. However, the goodness-of-fit test shows that, for example, in the GO categories 'response to abiotic stimulus', 'response to endogenous stimulus' and 'secondary metabolic process', the number of genes in $\mathrm{GC}_{3}$ rich and -poor categories differ from uniform distribution at $p$-value $=6.12 \mathrm{E}-13,6.68 \mathrm{E}-08$ and $1.56 \mathrm{E}-06$ respectively.

We calculated the distribution of nucleotides in the oil palm coding regions. The following models of ORF were considered: Multinomial (all nucleotides independent, and their positions in the codon not important), Multinomial position-specific and First order three periodic Markov Chain (nucleotides depend on those preceding them in the sequence, and their position in the codon considered). Additional file 2: Tables S4-S7 show the probabilities of nucleotides $\mathrm{A}, \mathrm{C}, \mathrm{G}$ and $\mathrm{T}$ in $\mathrm{GC}_{3}$-rich and -poor gene classes. Note that both methods predict 


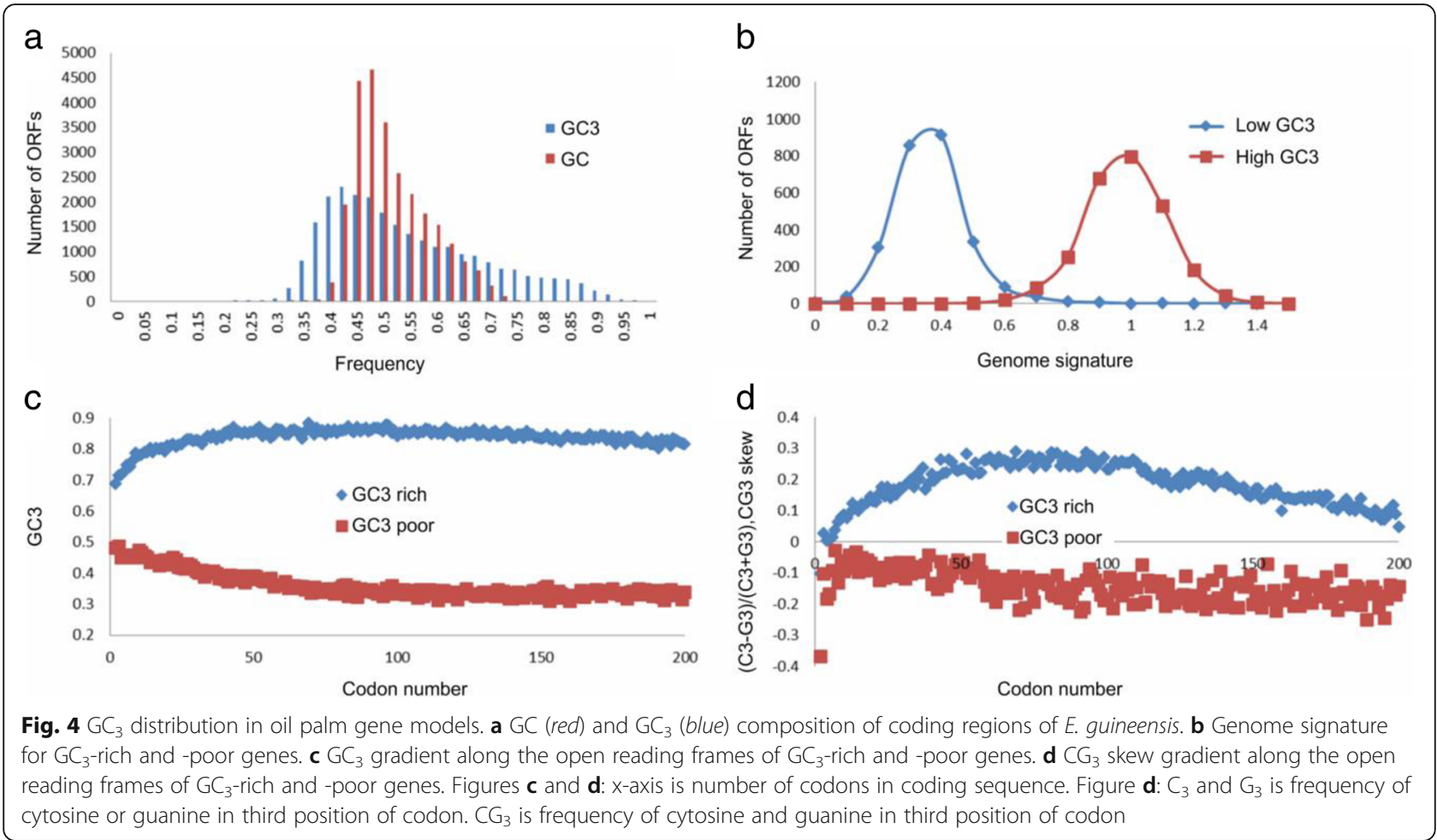

$\mathrm{GC}_{3}$-poor genes with greater imbalance between $\mathrm{C}$ and $\mathrm{G}$, than $\mathrm{GC}_{3}$-rich genes (0.05 vs. -0.1). This is consistent with the prior observation [102] that $\mathrm{GC}_{3}$-rich genes have more targets for methylation than $\mathrm{GC}_{3}$-poor genes, and that some cytosine nucleotides can be lost due to cytosine deamination.

$\mathrm{GC}_{3}$-rich and -poor genes differ in their predicted lengths and open reading frames (Additional file 2: Table S8). The $\mathrm{GC}_{3}$-rich genes have gene sequences and ORFs approximately seven times and two times shorter, respectively, than the $\mathrm{GC}_{3}$-poor genes. This is consistent with the findings from other species $[16,101,102]$. It is important to note that $\mathrm{GC}_{3}$-rich genes in plants tend to be intronless [16].

\section{Intronless genes (IG)}

Intronless genes (IG) are common in single-celled eukaryotes, but only a small percentage of all genes in metazoans [107, 108]. Across multi-cellular eukaryotes, IG are frequently tissue- or stress-specific, $\mathrm{GC}_{3}$-rich with their promoters having a canonical TATA-box $[16,102$, 107]. Among the 26,059 representative gene models with RefSeq and oil palm transcriptome evidence, 3658 (14.1\%) were IG. The mean $\mathrm{GC}_{3}$ content of IG is $0.668 \pm 0.005$ (Fig. 5), while the intron-containing (a.k.a. multi-exonic) genes' mean $\mathrm{GC}_{3}$ content is $0.511 \pm 0.002$, in line with the estimates for other species. IG are overrepresented among the $\mathrm{GC}_{3}$-rich genes $\left(\mathrm{GC}_{3}>=0.75286\right)$. $36 \%$ of intronless genes are $\mathrm{GC}_{3}$-rich, in comparison with an overall $10 \%$ in all oil palm genes (Chi-squared test $p$-value $\left.<10^{-16}\right)$. Intronless genes constitute $51 \%$ of the $\mathrm{GC}_{3}$-rich genes. Their CDS are, on average, shorter than multi-exonic CDS: $924 \pm 19$ nt vs. $1289 \pm 12$ nt. On average, there is one intronless gene per 9.5 multiexonic genes on any scaffold containing intronless genes. There is no difference in nucleotide composition and CpG frequency between short scaffolds that contain intronless genes, multi-exonic genes and no genes.

The distribution of IG in the whole genome is different for various functional groups $[16,108]$. For example, in the oil palm genome, $29 \%$ of the cell-signaling genes are intronless, compared to just $1 \%$ of all tropism-related genes (Additional file 2: Table S9). The distribution of genes by $\mathrm{GO}$ categories is similar to that in O. sativa. It has been shown that in humans, mutations in IG are associated with developmental disorders and cancer [108]. Intronless and $\mathrm{GC}_{3}$-rich genes are considered to be evolutionarily recent [16] and lineage-specific [107], potentially appearing as a result of retrotransposon activity $[108,109]$. It is reported that $8-17 \%$ of the genes in most animals are IG, $10 \%$ in mice and humans [107] and $3-5 \%$ in teleost fish. Plants have proportionately more IG than animals, $20 \%$ in O. sativa, $22 \%$ in $A$. thaliana [110], $22 \%$ in S. bicolor, $37 \%$ in Z. mays, $28 \%$ in foxtail millet, $26 \%$ in switchgrass and $24 \%$ in purple false brome [111]. We have independently calculated the fraction of IG in O. sativa, A. thaliana, S. bicolor and $Z$. mays using the currently published gene models 


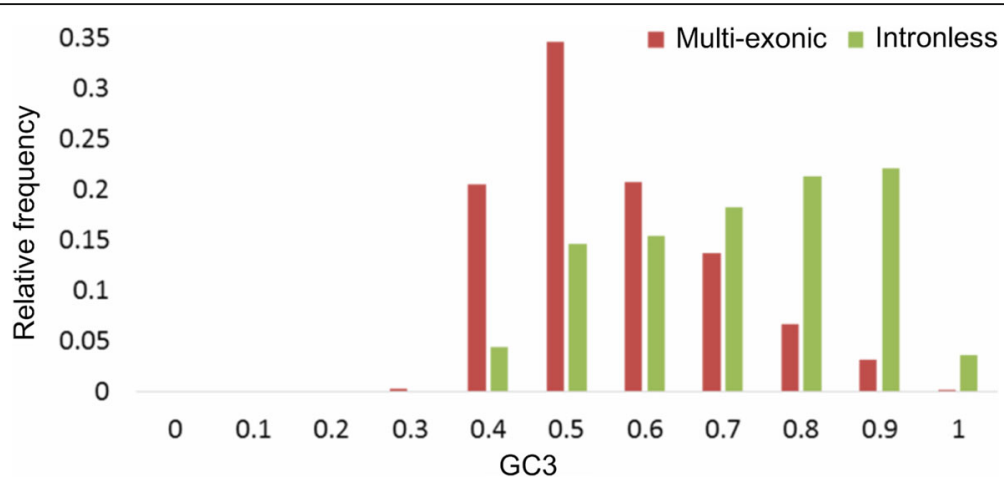

Fig. $5 \mathrm{GC}_{3}$ contents of oil palm intronless and multi-exonic genes

for each species, with results of $26 \%, 20 \%, 23 \%$ and $37 \%$, respectively (Additional file 2: Table S10). To establish a reference point, we calculated the fraction of IG in the green algae, $V$. carteri, and found $15.8 \%$. High IG in grasses is not surprising, since they have a clearly bimodal distribution of $\mathrm{GC}_{3}$ composition in their coding region, with the $\mathrm{GC}_{3}$-peak of this distribution dominated by IG [16].

Using BLASTP, we found 543 IG (14.84\% of oil palm IG) conserved across all the three domains of life: archaea, bacteria and eukaryotes (Fig. 6). These genes are likely essential for survival [112]. A total 736 oil palm IG had homologs only with eukaryotic and bacterial genes, while only 40 IG had homologs with eukaryotic and archaea genes (and not with bacteria). We speculate (due to the extreme growth conditions of archaea [113, 114]) that there are (1) fewer opportunities for horizontal gene transfer from archaea than from bacteria to the oil palm genome, and/or (2) possible ancestral gene loss on the archaeal branch in the process of adaptation. Considering three of the most economically important eukaryotic groups [Metazoa (animals), Fungi and Viridiplantae (green plants)] we observed 1373 oil palm IG shared among them. A significant portion of the oil palm IG (1863) was only homologous to Viridiplantae. These proteins may have evolved, or been regained, only in plants, even as other organisms lost their ancestral genes during evolution [110].

Reciprocal BLAST was carried out to verify the homologies of oil palm candidate IG to produce a set of high confidence oil palm IG. We found 2431 (66.46\%) proteins encoded by oil palm IG to have orthologs in $A$. thaliana, $O$. sativa or $Z$. mays that are also intronless, indicating that intronlessness is an ancestral state $[115,116]$. In conclusion, from our representative gene models, we estimate that about one-seventh of the genes in oil palm are intronless. We hope that this data will be a resource for further comparative and evolutionary analysis, and aid in understanding IG in plants and other eukaryotic genomes.

\section{Resistance (R) genes}

Plants differ from animals in many aspects, one of them is the lack of an antibody-based immune system. Instead,

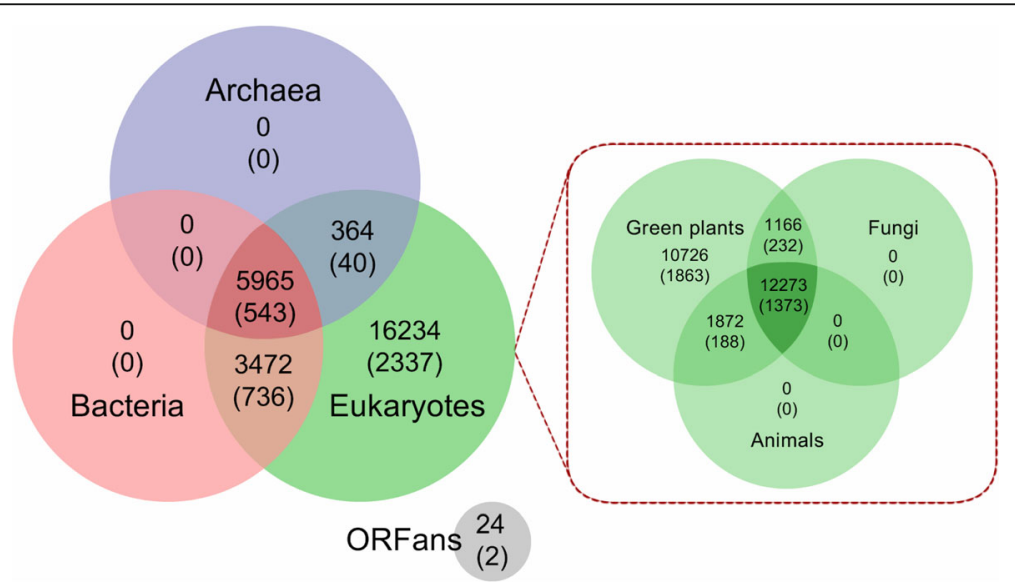

Fig. 6 Classification of oil palm intronless genes (IG) in different taxonomy groups. The Venn diagram shows the projections of 26,059 oil palm high quality loci and 3658 oil palm IG (in parenthesis) into three domains of life based on homology, archaea, bacteria and eukaryotes. The sub-diagram shows the distribution of oil palm IG from the eukaryote domain into three major taxonomy groups of life - Green Plants, Fungi and Animals. ORFans refers to the unique sequence that shares no significant similarity with other organisms 
they have protein-based mechanisms to recognize invading pathogens [117-119]. The genes encoding for such proteins are called "resistance", or " $R$ " genes. They play an important role in the plant's early detection and signaling mechanism against biotic and abiotic stresses. Using homology, we identified 210 oil palm candidate $R$ genes from the 26,059 representative gene models with RefSeq and transcriptome evidence (see Additional file 1 ). This is $\sim 0.80 \%$ of the high-quality genes identified in the oil palm genome, a similar ratio to that of an earlier study on the hypomethylated regions of the E. guineensis genome, where $52(0.94 \%)$ candidate resistance genes were identified among 5505 gene models [4]. A similar frequency was also observed in A. thaliana and O. sativa $-0.95 \%$ and $0.71 \%$ resistance genes, respectively. The oil palm candidate $\mathrm{R}$ genes were compared to those in banana (M. acuminata) and O. sativa, and 693 orthologs (253 in M. acuminata, 440 in O. sativa) were identified for 204 of the genes.

The candidate genes were divided into six classes by their protein domain structure [43]. Comparison of the distribution of oil palm candidate $\mathrm{R}$ genes with such genes identified using the same method in other plants showed that CNL class genes had the highest representation in monocots, with $O$. sativa having the largest percentage (51.8\%). A. thaliana, which is dicotyledonous, has two additional classes, TNL (Toll/interleukin-1 NBS-LRR) and RPW8-NL, while the colonial green algae $V$. carteri is missing most of the $\mathrm{R}$ gene classes in its genome. TNL, the most prevalent class in A. thaliana, is predominantly found in dicots [120]. The CNL and TNL classes both belong to the NBS-LRR family [121]. TNL can be differentiated from CNL based on the Toll/interleukin-1 (TIR) receptor domain at the $\mathrm{N}$-terminus structure [120].

We did not identify any TNL gene in the analyzed monocot genomes, including that of the oil palm. This is in line with Tarr and Alexander [122] who also did not find TNL genes in monocots. It is therefore assumed that $\mathrm{R}$ genes in monocots predominantly contain leucine zipper regions that facilitate formation of the conserved CC structure at the N-terminal of NBS-LRR genes, as previously indicated [123]. The CC domain is required for protein-protein interaction [46] while the LRR domain interacts with the avirulence (Avr) gene product from pathogens to activate the plant defense system [124]. Plants producing specific $R$ genes are resistant to pathogens which produce the corresponding Avr gene products. The fraction of $\mathrm{R}$ genes across the plant genome suggests the importance of these genes for both monocots and dicots (Fig. 7a).

$\mathrm{CNL}$ genes form the most abundant class in the oil palm genome. A total 141 genes were identified, of which 133 have orthologs in other plants. The remaining eight are unique to the oil palm and may be involved in palmspecific interactions with pathogen Avr gene products.
Validation using multiple sequence alignments of the oil palm CNL genes and their orthologs showed a conserved kinase-2 motif with the last residue W (Tryptophan) in the NBS domain in most of the oil palm CNL genes. Of the 141 oil palm CNL genes, only nine do not have the final residue, $\mathrm{W}$. The $\mathrm{W}$ residue is highly conserved in non-TIR NBS-LRR genes [120]. The percentage of CNL genes (67.14\%) agrees with Staskawicz et al. [125] who reported that the majority of disease resistance genes in plants contain the NBS-LRR domain [126].

Another class of $\mathrm{R}$ genes critical for plant defense is the Kinase class. This class contains an intracellular serine/ threonine protein kinase (STK) domain which plays an important role in many plant processes, including plantpathogen interaction $[46,48,127,128]$. Pto, an R gene previously identified in the tomato genome to confer resistance against Pseudomonas syringae pv. tomato strains, is a Kinase $[47,129]$. There are several features defining the Pto gene in tomato - Pto activation domain [127], autophosphorylation sites [46, 48, 127], P + 1 loop [129] and Nmyristoylation motif [128]. Seven candidate genes in the oil palm genome have the required features. Sequence alignment between the candidate genes and Pto revealed several highly conserved sites in the Pto activation domain. However, the third autophosphorylation site in the activation domain had a threonine to glycine mutation (Additional file 3: Figure S2), which was reported to reduce the plant hypersensitive response [127].

The remaining $R$ genes identified were RLP, RLK and Mlo-like. The high-quality oil palm dataset contains three RLP and three RLK genes. Both classes contain the transmembrane and LRR domains [46], but only RLK an additional STK domain (Fig. 7b). RLP and RLK genes function as pattern recognition receptors (PRRs) in the transmembrane region, and are activated in the initial detection of a pathogen in the plant $[130,131]$. Other plants, such as A. thaliana (9.8\% RLK and 4.0\% RLP) and O. sativa (10.5\% RLK and 5.4\% RLP), have higher percentages of these genes in their genomes. Since none of the oil palm transcripts used in the gene prediction process originated from stress-related tissues, the number of predicted R-genes may be under-estimated. The actual percentage of these two classes may be higher, but only the six identified RLK and RLP genes were expressed in the transcriptomes used. Oil palm also has 13 candidate Mlo-like genes, classified by having the Mlo domain [46]. The first member of this class, $M L O$ gene from barley, was expressed in leaf in response to invasion by a fungal pathogen, Erysiphe graminis f sp. Hordei. MLO (mildew locus $\mathrm{O}$ ) is an intrinsic protein with six transmembrane regions [132] while the palm MLO-like candidates have six/seven transmembrane regions.

About $70 \%$ of the 210 candidate $R$ genes were distributed across the 16 oil palm chromosomes of the EG5 


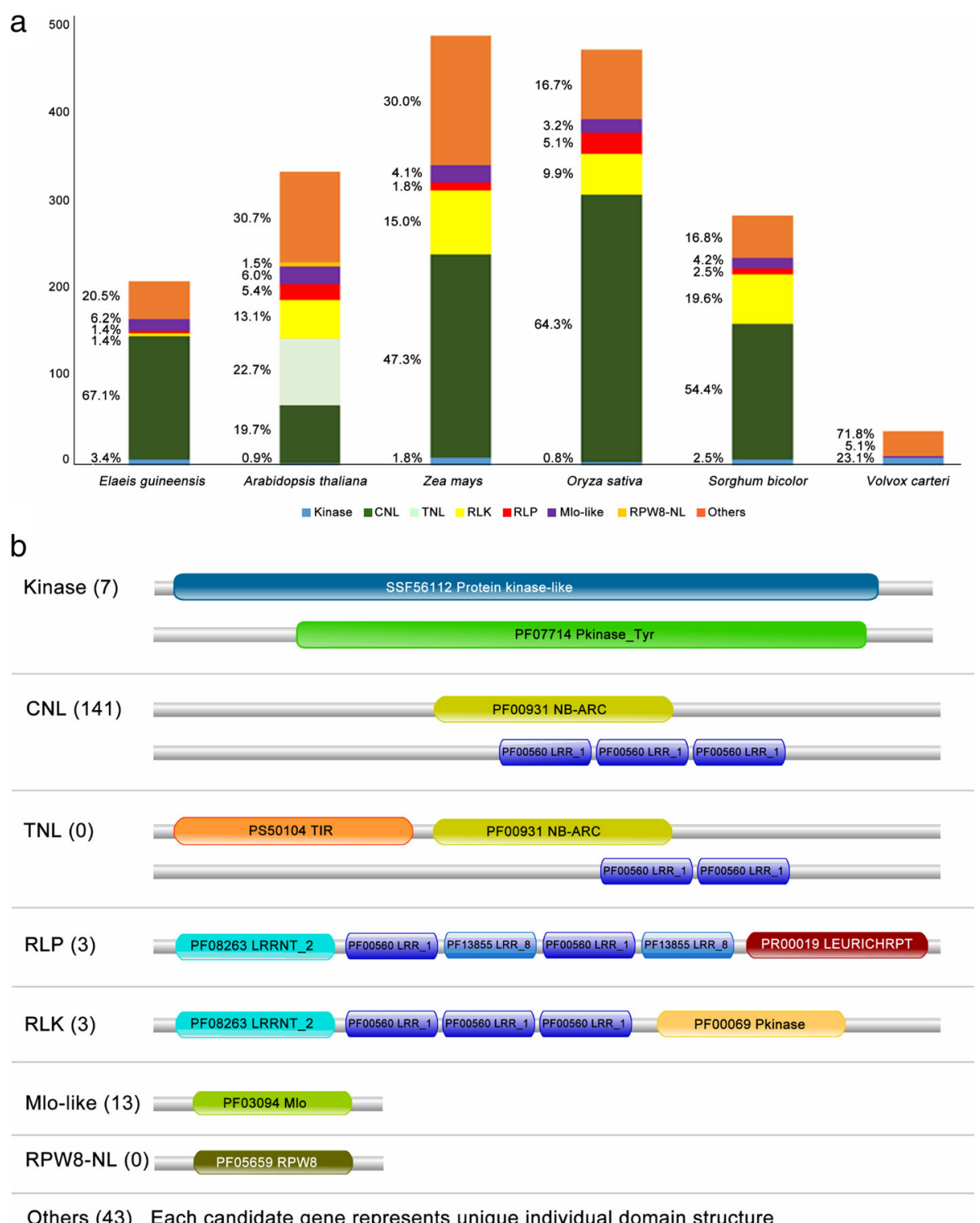

Fig. 7 Classification of candidate R genes. a Distribution of the genes in oil palm, A. thaliana, Z. mays, O. sativa, S. bicolor and V. carteri b Examples of key domains identified via InterProScan in oil palm candidate R-genes. Number of identified candidate oil palm genes are in brackets

genome build [5] (Additional file 3: Figure S3). One hundred one of the $141 \mathrm{CNL}$ class $\mathrm{R}$ genes were found on 14 of the chromosomes, of which 62 formed 23 clusters by chromosomal location. The highest number of clustered CNL class R genes (42\%) were on chromosome 2. R genes in other plants (such as thale cress, flax, barley, lettuce, maize, potato, rice, soybean and tomato) also form location clusters [133]. Plant resistance is determined by (direct or indirect) interaction of the plant $\mathrm{R}$ genes with pathogens' Avr genes, and evolves to adapt to the different forms of Avr genes [124, 134]. Colocated $\mathrm{R}$ genes recognize different pathogens and are hypothesised to share function and pathogen recognition systems [133].
Since $\mathrm{R}$ genes are important for the plant survival and its surveillance system, the $R$ genes-related domains appear to be evolutionarily conserved across all sequenced plant genomes, including that of oil palm. The high-quality dataset was used to find the necessary domains to classify the $\mathrm{R}$ genes into six classes. Identification of these candidate genes is useful for marker development and gene expression studies during infection, especially for basal stem rot, one of the most devastating oil palm diseases in South-East Asia. Comparing the oil palm genome with those of other monocots, it was possible to identify $\mathrm{R}$ genes for further functional characterization, and reveal homologous sequences in related crops. 


\section{FA biosynthesis genes}

Oil palm is unique in that it produces different oils with distinct fatty acid profiles in its mesocarp and kernel. The E. guineensis mesocarp oil is $\sim 50 \%$ saturated (39.245.8\% palmitic acid [C16:0], 3.7-5.1\% stearic acid [C18:0] and 0.9-1.5\% myristic acid [C14:0]), 37.4-44.1\% monounsaturated (mainly oleic acid [C18:1]) and 10.5\% polyunsaturated (10.2\% linoleic acid [C18:2] and 0.3\% linolenic acid [C18:3]) [135]. The kernel oil is more saturated, with mainly medium chain fatty acids - lauric ([C12:0], 44\%), myristic $(\sim 15 \%)$ as well as palmitic $(\sim 8 \%)$ acid [136]. Kernel oil also contains about $15 \%$ oleic acid. The fatty acid compositions also vary noticeably between E. guineensis and E. oleifera $[137,138]$. E. oleifera mesocarp oil is typically less saturated $(53.5-68.7 \%$ oleic acid, 11.9\%-26.9\% linoleic acid and 0.0\%-1.9\% linolenic acid) [138]. Forty-two oil palm (E. guineensis) genes involved in FA biosynthesis, including two multifunctional acetyl-CoA carboxylases (ACCase), were identified (see Additional file 1). Figure $8 \mathrm{a}$ and $\mathrm{b}$ show the numbers of oil palm genes in the FA biosynthesis pathway, and oil palm fatty acid composition respectively. The conserved catalytic residues were identified via sequence alignment of the corresponding amino acids (Additional file 3: Figures S4-S15). This method was used by Li et al. [65] to study the candidate FA biosynthesis genes of Arachis hypogaea L. Twenty seven FA biosynthesis genes were categorized in 10 classes based on the conserved catalytic residues of their corresponding amino acid sequences, and six identified by their conserved motifs. The remaining nine genes encoding ACCase were mainly classified by homology. Using a $70 \%$ identity cut-off, 39 candidate oil palm FA biosynthesis genes had 94 corresponding orthologs in A. thaliana (29) and $Z$. mays (65). Overall, these results showed that the classifications were consistent with the annotations of $A$. thaliana and $Z$. mays genes. The three remaining candidate genes, one acyl-ACP thioesterase (EgFATB_1) and two stearoyl-ACP desaturases (EgFAB2_3 and EgFAB2_4), were defined as singletons. Closer examination of EgFAB2_3 indicates that the gene could be truncated, as it had a gap in its genomic region, making it a singleton.

ACCase plays an important role in de novo FA biosynthesis as it catalyzes the first committed step in the pathway [139]. Analysis of the ACCase genes showed that oil palm contains both the multi-subunit (CT [3 copies], BCCP [2 copies], BC [2 copies]), and multifunctional ( 2 copies) forms. This agrees with Wan Omar et al. [140]. who reported two distinct forms of ACCase in oil palm. After the first committed step, stepwise addition of two-carbon residues from malonyl-ACP continues until palmitoyl-ACP (C16:0-ACP). C16:0-ACP is then converted to $\mathrm{C} 18: 0-\mathrm{ACP}$ by $\beta$-ketoacyl-ACP synthase II (FABF) [141]. Biochemical analysis showed that the FABF activity, and level of $\mathrm{C} 18: 1$ are negatively related with the level of C16:0 [136]. FABF activity in E. guineensis was

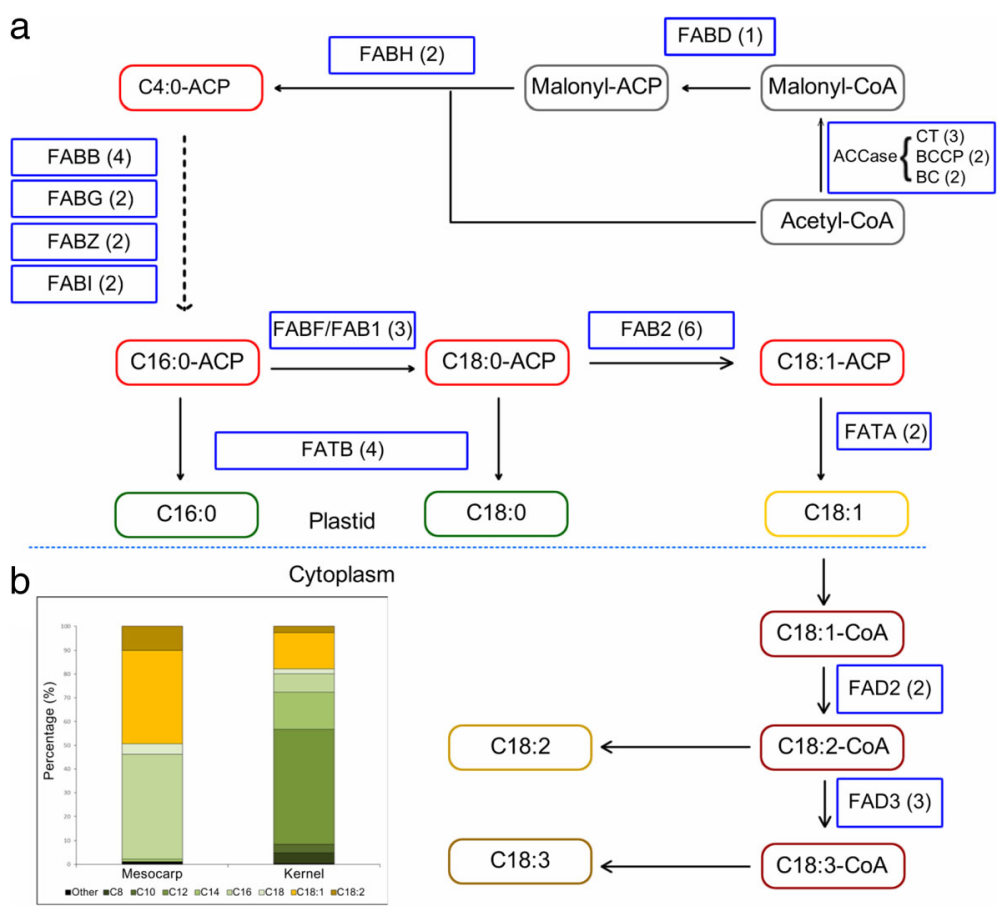

Fig. 8 Fatty acid biosynthesis in E. guineensis a Schematic pathway diagram for fatty acid biosynthesis. Numbers of identified oil palm candidate genes are in brackets. $\mathbf{b}$ Fatty acid composition in mesocarp and kernel 
only $<50 \%$ of several accessions of E. oleifera [136]. Although E. guineensis has three copies of $F A B F$, expression analysis showed a dominant copy in the mesocarp and kernel. EgFABF_1 is at least $2.8 \times$ and $19.2 \times$ more highly expressed in mesocarp and kernel respectively than the other two copies (Fig. 9a), suggesting that the conversion of C16:0-ACP to C18:0-ACP is mainly driven by it. Overexpression of this gene copy may drive palm oil to higher oleic acid content. The second copy of $F A B F$, $E g F A B F_{-} 2$, is also expressed in both the mesocarp and kernel samples but at lower levels. This is in line with Umi Salamah et al. [142] who reported that the $F A B F$ identified, similar to EgFABF_2 (93\% identity at nucleotides level), was also expressed in both mesocarp and kernel samples at relatively higher levels than in other tissues using northern blot analysis. The remaining EgFABF_3 has very low expression.

Stearoyl-ACP desaturase (encoded by FAB2 [143-145]) plays a crucial role in determining the ratio of saturated to unsaturated $\mathrm{C} 18$ fatty acids in plant membranes and storage lipids. Multiple alignment of the corresponding amino acid sequences of the oil palm and other plants $F A B 2$ genes identified two important motifs (EENRH and DEKRH). In this study, the $F A B 2$ gene has the highest number of copies among all the FA biosynthesis genes identified. This is not unexpected as oil palm has moderate oleic acid in both its oils, $\sim 40 \%$ in its mesocarp oil and $\sim 15 \%$ in its kernel oil. FAB2 is a very active enzyme in the developing oil palm mesocarp and any effort to increase the oil oleic acid content may not therefore require upregulating the gene(s) expressing stearoyl-ACP desaturase [135]. Ortholog analysis showed that two oil palm FAB2 genes (EgFAB2_3 and $\left.E g F A B 2 \_4\right)$ are singletons while four (EgFAB2_1, EgFAB2_2, EgFAB2_5 and EgFAB2_6) are similar to orthologs in A. thaliana and $Z$. mays.

EgFAB2_1, EgFAB2_5 and EgFAB2_6 are in the same clade as FAB2 genes encoded by AT2G43710 (SSI2), AT5G16240 (S-ACP-DES1) and AT3G02630 (S-ACPDES5) in A. thaliana (Fig. 10). This is interesting because SSI2 is involved in determining the 18:1 pool in A. thaliana leaf [146] and has a substrate preference for C18 over C16 fatty acids [146, 147]. Surprisingly, EgFAB2_1 has the highest expression in the mesocarp and kernel (Fig. 9b), suggesting that it is the dominant copy of the $F A B 2$ gene, and

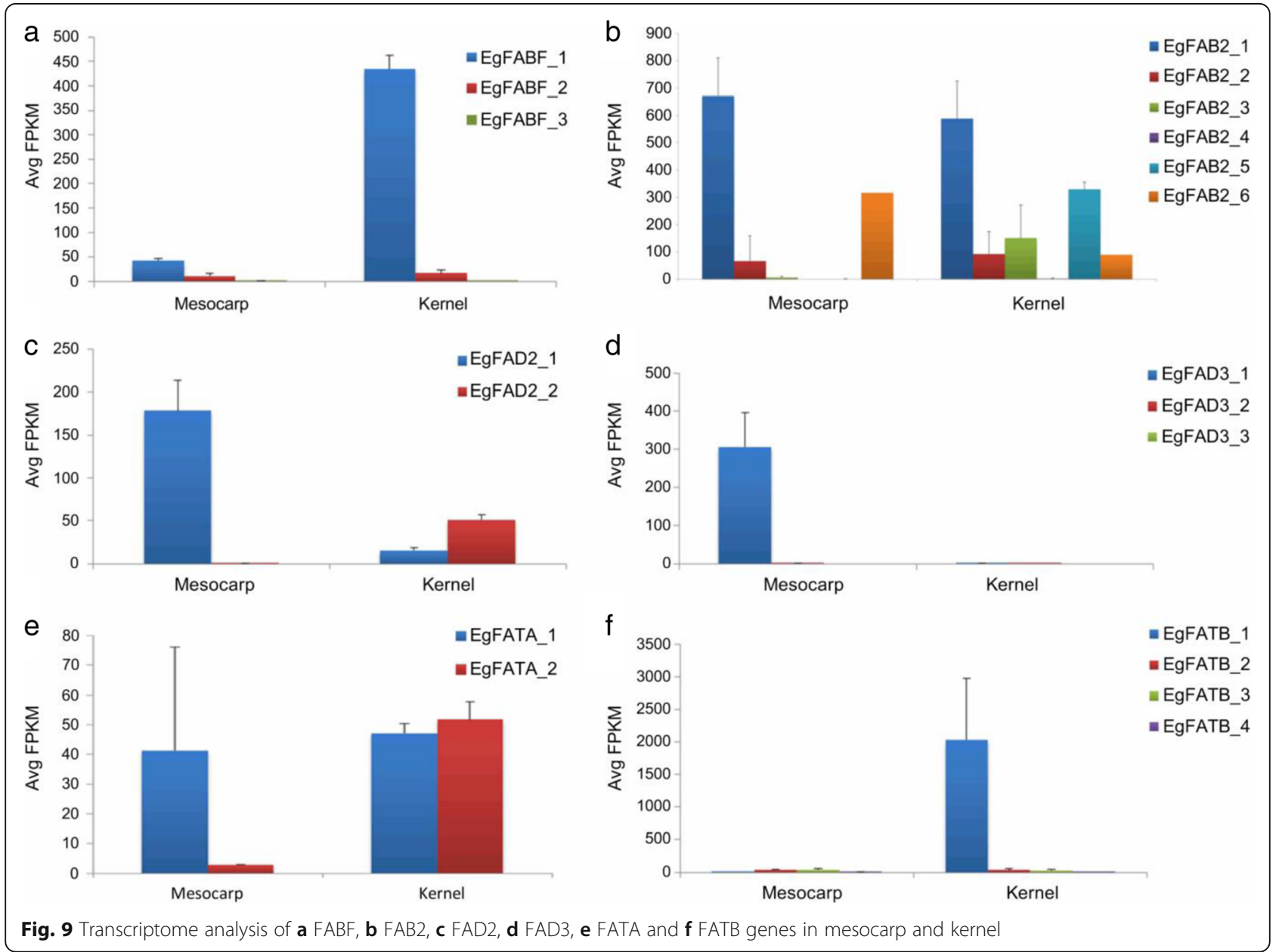




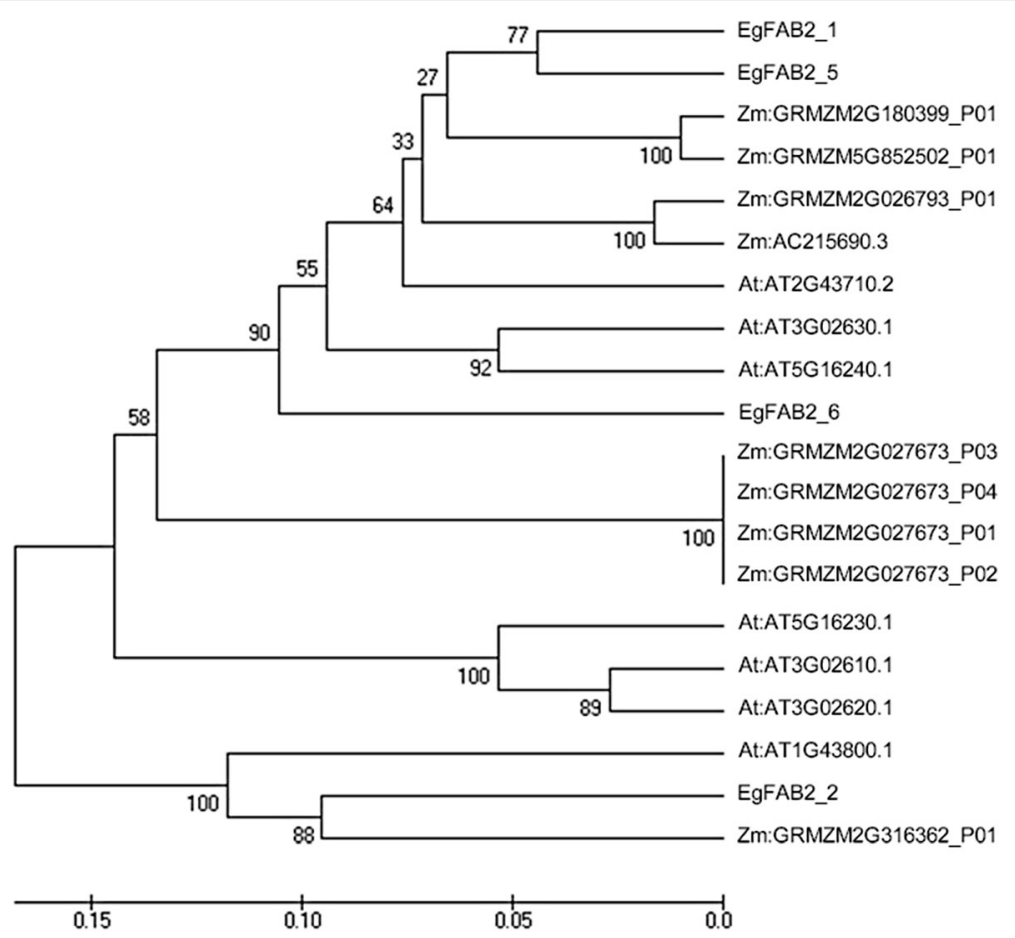

Fig. 10 Evolutionary relationship of FAB2 in oil palm (E. guineensis), A. thaliana and Z. mays. Analyses carried out using UPGMA method in MEGA 6 software. Abbreviations: Eg - E. guineensis; At - A. thaliana; Zm - Z. mays

largely responsible for desaturating $\mathrm{C} 18: 0-\mathrm{ACP}$ to $\mathrm{C} 18: 1-$ ACP in de novo FA biosynthesis in the tissues. EgFAB2_6 also has a relatively high expression in the mesocarp, but is lower in the kernel. The gene may also contribute to the production of C18:1-ACP in the mesocarp, as knocking out SSI2 in A. thaliana only reduced the desaturase activity by 90\% [146]. EgFAB2_3 and EgFAB2_5 are hardly expressed in the mesocarp, but highly in the kernel, indicating tissue specific expression. Both may play a more important role in C18:1 production in the kernel than mesocarp. EgFAB2_2 has the highest divergence from the other four genes in the phylogenetic tree, and is orthologous to the A. thaliana gene, AT1G43800. Northern analysis of AT1G43800 in A. thaliana showed that the gene is not expressed in the leaf, stem, root, flower or silique [146]. This is in line with the oil palm 454-transcriptome data, which showed that EgFAB2_2 is not expressed in the leaf, root or stalk, with only slight expression in the flower (data not shown). Based on expression analysis, EgFAB2_2, like EgFAB2_3, and EgFAB2_5 may play more important roles in C18:1 production in the oil palm kernel than mesocarp. The remaining copy of the FAB2 gene (EgFAB2_4) has very low expression in the mesocarp and kernel.

C18:1 may be further desaturated to polyunsaturated fatty acids in the plastid or endoplasmic reticulum (ER). FAD2 and FAD3, localized in the ER, are responsible for the synthesis of $\mathrm{C} 18: 2$ and $\mathrm{C} 18: 3$, respectively, in storage oils. EgFAD2_1 and EgFAD3_1 are the dominant copies of $F A D 2$ and $F A D 3$, respectively, that probably drive the desaturation of C18:1 in the mesocarp (Fig. 9c-d). The expression data showed higher FAD2 and FAD3 expression in the mesocarp than kernel, consistent with the fact that the mesocarp oil contains some C18:2 and C18:3, both of which are insignificant in kernel oil.

Acyl-ACP thioesterases terminate de novo chain elongation by hydrolyzing the acyl-groups on acyl-ACP fatty acids $[148,149]$. The unesterified fatty acids released are exported to the ER for modification, such as assembly into triacylglycerols and/or membrane lipids. Thioesterases are either FATA or FATB, depending on their specificity for acyl groups - FATA prefers unsaturated and FATB saturated. Six oil palm acyl-ACP thioesterase genes were identified. The corresponding amino acid sequences of the genes contain two conserved motifs, NQHVNN and YRRECG. However, the conserved YRRECG motif in oil palm and other plants differed from the PFAM HMMLogo (Additional file 3: Figures S14 and S15), in line with Voelker et al. [150], who postulated plant thioesterases as a different class of enzymes from those of animals and bacteria. Multiple alignment, BLAST, and ortholog analysis of the corresponding amino acid sequences (Additional file 3: Figure S16) were able to classify EgFATA_1 and EgFATA_2 as oleoyl-ACP thioesterase (FATA) genes. EgFATA_1 and EgFATA_2 are highly similar to experimentally derived oleoyl-ACP thioesterase AAD28187.1 in E. guineensis [151], with $97 \%$ and $89 \%$ BLASTP identity respectively, and to 
NP_001292940.1 from J. curcas (69\% identity, 76\% positives) and XP_007049712.1 from T. cacao (72\% identity, 90\% positives). Both these sequences have high homology and formed a clade with other characterized plant FATA genes. The remaining four could not be differentiated via sequence analysis but expression data suggested that they function as FATB to hydrolyze saturated acyl-ACPs. EgFATB_1 is not expressed in the mesocarp but has very high expression in the kernel, indicating that it is mainly involved in fatty acid chain termination in the kernel (Fig. 9f).

As oil palm accumulates $48 \%$ C12:0 and 15\% C14:0 in its kernel oil, EgFATB_1 probably encodes for a thioesterase with substrate specificity for medium chains, i.e. lauryl- or myristoyl-ACP thioesterase. EgFATB_2 and EgFATB_3, only moderately expressed in the mesocarp and kernel, are probably involved in the formation of C16:0 since the acid accumulates to $44 \%$ in the mesocarp oil and $15 \%$ in the kernel oil. The remaining acyl-ACP thioesterase (EgFATB_4) was only detected at very low levels in both the mesocarp and kernel, and may code for stearoyl-ACP thioesterase as palm oil and palm kernel oil only contain 3.7-5.1\% [135] and $0.5-5 \%$ [152] stearic acid, respectively.

Comparison of the genomic locations of the FA biosynthesis genes in the oil palm genome showed that three genes, namely $E g F A B F$, $E g F A B H$ and $E g F A D 3$, showed duplication events (Additional file 3: Figure S17). This is in accordance with the segmental duplications of chromosome arms reported by Singh et al. [5]. The study identified and characterized 42 key genes involved in FA biosynthesis in $E$. guineensis. This is the first study to identify key FA biosynthesis genes in both the oil palm mesocarp and kernel through sequence and gene expression analysis. The comprehensive information will help pave the way to an understanding of the different mechanisms involved in producing the unique fatty acid profiles of palm mesocarp and kernel oils.

\section{Conclusions}

An integrated gene prediction pipeline was developed, enabling annotation of the African oil palm genome, and deriving a set of 26,059 high quality and thoroughly validated gene models. BUSCO analysis showed that our high-quality gene models contain at least $90 \%$ of the known conserved orthologs in eukaryotes, making our gene prediction collection the most reliable annotation of the oil palm genome. With the results, we conducted an in-depth analysis of several important gene categories: intronless, resistance and FA biosynthesis. The prevalence of these groups was similar across several plant genomes, including those of A. thaliana, Z. mays, O. sativa, S. bicolor, G. $\max$ and R. communis. Coding regions of the oil palm genome have a characteristic broad distribution of $\mathrm{GC}_{3}$, with a heavy tail extending to high $\mathrm{GC}_{3}$ values that contain many stress-related and intronless genes. $\mathrm{GC}_{3}$-rich genes in oil palm are significantly over-represented in the following GOslim process categories: responses to abiotic stimulus, responses to endogenous stimulus, RNA translation, and responses to stress. We found approximately oneseventh of the oil palm genes identified to be intronless. Two hundred ten $\mathrm{R}$ genes grouped in six classes based on their protein domain structures were also identified. Lipid-, especially FA-related genes, are of interest in oil palm where, in addition to their roles in specifying oil yield and quality, also contribute to the plant organization and are important for biotic and abiotic stress signaling. We identified 42 key genes involved in oil palm FA biosynthesis, which will be especially useful for oil palm breeders.

The results from our study will facilitate understanding of the plant genome organization, and be an important resource for further comparative and evolutionary analysis. The study of oil palm genes will facilitate future advances in the regulation of gene function in the crop, and provide a theoretical foundation for marker-assisted breeding for increased oil yield and elevated oleic and other valuable fatty acids.

\section{Reviewers' comments}

Reviewer' report 1: Alexander Kel, Genexplain, Germany Reviewer comments

In this paper, the authors have successfully annotated the oil palm genome with high quality annotation of over 26 thousand genes. An important novelty of the approach is application of two independent gene prediction pipelines Fgenesh++ and Seqping that are best available, at least for plant genomes. The gene prediction is combined with many additional lines of evidences, applying really a big number of various tools, that makes it a top quality genome annotation initiative. Very important is that the authors combined the pure computational efforts with the experimental transcriptomics analysis (using RNA-seq) which helped them to perform better gene annotation and also gives additional possibility for functional interpretation of the results. In summary, I am recommending this manuscript for rapid publication, which will provide the community with a new rich resource for analysis of these very important genome.

1) The own tissue-specific RNA-sequencing data (from MPOB) used in the paper should be better described. Ideally in a separate section.

Author's response: We thank the reviewer for the kind suggestion and have added the list of the RNA-sequencing libraries in Additional file 1.

2) Rules of integration between results of the two pipelines used should be also a bit better described. The Table 2 is a little bit confusing. Perhaps an example with overlapping gene models coming from two different tools could be helpful for the reader.

Author's response: To merge pipelines, we looked at clusters of genes with continuous overlap within the 
cluster at different percentages of the length. Each gene in the cluster overlaps with at least one other gene from the cluster at a given overlap threshold (single linkage approach). ORF predictions with $<300$ nucleotides were excluded. We tested different overlap thresholds from $60 \%$ to $95 \%$ in 5\% increments, as shown in Fig. 2. Gene models from the same strand predicted from the two pipelines are considered to belong to the same locus if the gene models within the locus overlap at the selected threshold with at least one other gene in the locus. In a locus, gene models can overlap at different regions as shown in Additional file 3: Figure S1a. Gene models that do not meet the overlap threshold will form different sets of genes (Additional file 3: Figure S1B). Overlap of 85\% was selected as the best threshold, as the rate of increase in the number of single gene loci was higher after this threshold level. The representative gene model for each locus was selected based on the gene model with the lowest E-value comparison to RefSeq in the respective locus. The details of how the representative gene models are selected are described in Methods section (Line 246-263).

3) Concerning the intron-less genes (IG). I think that more explanations are needed to argue that the IG genes are actually "working" genes in genome, but not possible pseudo-genes. As we can see from the Table 1, only a fraction of the predicted genes has got evidence from the transcriptomics and RefSeq that they are actually transcribed. What is the fraction of IG genes has got such evidence?

Author's response: The IG genes that were characterized in the manuscript originated from the 26,059 representative genes models with both RefSeq and oil palm transcriptome evidence. They are from the "high-confidence" subset of all genes presented in the Fig. 1. This is also mentioned in Line 358-360. Table 1 was changed to a flow chart (Fig. 1) to improve clarity.

\section{Reviewer's report 2: Igor Rogozin, NIH, USA Reviewer comments}

The paper describes a new annotation of 26,059 oil palm genes using two independent gene-prediction pipelines, Fgenesh ++ and Seqping. The authors identified 42 key genes involved in FA biosynthesis in oil palm. For three of these genes, namely EgFABF, EgFABH and EgFAD3, recent duplication events were detected.

1) I would define GC3 in the Abstract.

Author's response: The description of $G C_{3}$ has been added to the Abstract (Line 109).

2) "with a heavy tail of high $\mathrm{GC}_{3}$ regions harboring many intronless and stress-related genes..." Is this result supported by statistical test(s)?

Author's response: Additional text had been added in the $G C_{3}$ (Line 442-443) and $G O$ analysis (Line 415-423) sections to address this issue. 36\% of the intronless genes were $G_{3}$-rich while $G O$ analysis showed that there were higher representations of stress-related genes in the $\mathrm{GC}_{3^{-}}$ rich gene set as compared to all the oil palm genes.

3) "Our analysis indicates that de novo FA biosynthesis in the oil palm mesocarp and kernel is driven primarily by EgFAB2_1." I am not sure that the authors have enough support for this statement. Maybe I missed something.

Author's response: We agree with the reviewer and have removed the statement. In the results section, the gene is listed as "the dominant copy of the FAB2 gene, and largely responsible for conversion of C18:0-ACP to C18:1-ACP in de novo FA biosynthesis in the oil palm mesocarp and kernel" as it has the highest expression in both tissues. We thank the reviewer for his comments.

4) Conclusions in the Abstract looks too general: "...while providing theoretical foundation for markerassisted breeding of this globally important crop". The authors may try to make this section more specific.

Author's response: We are grateful to the reviewer for his recommendations and have edited the Conclusions section in the Abstract to better reflect the manuscript.

\section{Reviewer's report 3: Vladimir A. Kuznetsov, Bioinformatics Institute, Singapore \\ Reviewer comments}

In this study, the authors develop an integrated genefinding framework and applied it to identify high quality oil palm gene models using the pisifera scaffold assembly and combining mapping pipelines. The best gene model for each locus was selected to establish a representative "high confidence" gene set. This paper provides identification and characterization of the "high confidence" set of 26,059 oil palm genes that have transcriptome and RefSeq support, and is supported by bioinformatics analysis of the genes. The study includes comparative genomics and regular bioinformatics analyses, statistical tests and new database. It is a well- designed and interesting study. However, several important statements, results and their interpretation have to be clarified and improved.

1) I suggest to revised the Abstract. Background. Replace a common introduction sentences "Emergence of rapid and inexpensive DNA sequencing technology has led to an avalanche of data waiting to be transformed into valuable insight about genome organization and function. A typical starting point for genome analysis is, customarily, annotation" onto more specific scientific problem(s) in the oil palm genome biology (e.g., accurate gene annotation) and the alignment of the methods and results to the palm oil industry needs (oil yields and quality) and/or economic efficiency of the industry. "This paper presents a study of the oil palm genome, including comparative genomics analysis, along with the development of the relevant database and $<$ bioinformatics> tools." Method section information is not present. 
Results: The sentence "Our analysis indicates that de novo FA biosynthesis in the oil palm mesocarp and kernel is driven primarily by EgFAB2_1." is too strong for a bioinformatics paper. Conclusions. The conclusion is week and is not specific. The phrase "The study of oil palm genome will facilitate further understanding of its genetic regulation" is not a main result of this study. The phrase "providing theoretical foundation" is not correct in the context of the aims of this study.

Author's response: We agree with the reviewer and have edited the Abstract. The Background section had been changed to provide some information on the oil palm and the reasons for the study. Although we do not have a Methods section, which is in line with the requirements of the journal, the methods used had been incorporated into the Results section. We agree with the reviewers that the statement for EgFAB2_1 is too strong and have removed it. The conclusions have also been edited to better reflect the manuscript.

2) Information about database should be included in the Method/Result sections.

Author's response: Information on how to access the database is available in the Declaration section. We have also added this information in the Abstract section. Information on the database has also been added to the Results section (Line 360-364) and Additional file 4.

3) Three-four major results should be summarized in the conclusion.

Author's response: We thank the reviewer for the constructive comment and have edited the Conclusions section in the Abstract to better reflect the manuscript.

4) Introduction Goals: You should better specify a goal and problem's vision. For example, the objectives of the programme complex and the database may be: 1 . To develop a high standard gene reference/annotation system for the oil palm genome analysis. 2. To map the genes and regulatory DNA signals/sequences associated with important agronomic traits. 3. To develop and use the genome information to solve the disease and stress resistant palms with enhanced productivity.

Author's response: The final paragraph of the Introduction section has been edited to better reflect the goals of the project.

5) Methods The workflow for the gene prediction method and the data analysis should be included.

Author's response: We have improved the Methods section to provide more details of the processes used and added the flowchart of the pipeline. The details of the gene prediction are described in the Methods section under the headers "Fgenesh++ Gene Prediction" and "Seqping Gene Prediction". The processes to integrate the gene models from both pipelines are described in the "Integration of Fgenesh++ and Seqping Gene Predictions" section.
6) Database. In fact, you did not use your DB to support the results. The DB should be more important part of your work, to be described and actively used in the study. You may provide the figure(s) showing Web interface and add user-friendly help/ comment information. A few examples (figure(s)) of the useful tracks supporting the major statements (known important and novel genes, joint tracks of the gene models and transcription data and key regulatory signals etc.) could make this study more interesting and attractive.

Author's response: The database, PalmXplore is an integrated database system that allows researchers to search, retrieve and browse the oil palm gene information and associated functional annotations using a convenient interface and fast database on the back-end. It was developed as a tool for researchers to easily search and access the results of this study. The URL of the database is available in the Abstract and Declaration section. We have also added additional information on the database in the Results section (Line 360-364) and Additional file 4.

7) pp.8-9 Reproducibility and availability issues: Information about the "high confidence" gene set, chromosome coordinates of these genes should be available in (new) master table. Information about gene structure and annotation shown for the intronless, two and more exons genes could be useful for future studies. p.11 "all genes by their GC3 content and designated the top $10 \%$ (2,605 ORFs) as GC3-rich (GC3 $\geq 0.75)$, and the bottom $10 \%$ as GC3-poor $(\mathrm{GC} 3 \leq 0.37)$." Reproducibility and accessibility of main data/results is an important issue. Could you please include in (new) master table data for 2605 ORFs with explicit presentation of the GC3-rich and GC3-poor, and GC-skew characteristics of the genes/transcript isoforms, specifying the intron-less and multiple exon genes, UTRs, exon and intron locations? The data base should be also updated accordingly. The including help file, summary statistics and a few examples will be much appreciated.

Author's response: We have included a table in Additional file 1. The location and structure of the genes is available in the PalmXplore database. The URL of the database has been included in the manuscript.

8) p. 11 and Fig. 3. "Despite the relatively small number of the GC3-rich genes in the oil palm genome, there are characteristic patterns of positional gradients (Fig. 3c and d) near the predicted start of translation...”. Fig. 3c and $\mathrm{d}$ does not provide information about the frequency distribution of GC3 in upstream or downstream regions of the transcription start site (TSS). You should construct that frequency distribution function using the GC-skew sequence data for TSS of the annotated genes of interest. 
Author's response: GC3 is a frequency of cytosines and guanines in the third position of codon. It is therefore only used to define the cytosines and guanines levels of the coding regions. The present manuscript focuses on the generation, characterization and annotation of high quality gene models or the genic regions of the oil palm genome. Although we agree that characterization of the promoter region is important, it is not within the present scope of the manuscript. We are currently working on the best method to predict the TSS and promoter regions accurately.

9) p.11 and Fig. 3d CG3 skew gradient along the open reading frames of GC3-rich and -poor genes. Axis Y shows the CG-skew score calculated by Eq. CGskew $=(C-G) /(C+G)$. However, in the main text this formula was not introduced and discussed; instead, CG3-skew $=(\mathrm{C} 3-\mathrm{G} 3) /(\mathrm{C} 3+\mathrm{G} 3)$ was introduced and discussed, where the C3 and the G3 were not defined. Please explain and make appropriate corrections.

Author's response: We thank the reviewer for the comment. There was a typo error in the y-axis of Fig. 3 (now Fig. 4) and it has been corrected. Fig. 3d (now Fig. 4d) now shows CG3-skew. We have also added an explanation in the figure legend.

10) p.11 Analysis of the GC contents, GC-skew characteristics in exons are not enough to characterise the regulatory signals and biological complexity of the genes at the genome and transcriptome scales. For the identification of gene regulatory signals, specifically for the transcription initiation and termination, it is important to analysis the GC-skew regions and the G-rich clusters in the proximal promoter regions of a gene, gene body, downstream gene region (not only the exons). These kinds of signals can provide specific gene expression regulation often associated with the transcriptional R-loop formation sequences. It has been shown that the R-loop formation structures (RLFS) could be reliably identified/predict by QmRRFS tool [Wongsurawat et al., NAR, 2012; Jenjaroenpun et al., NAR, 20,015], predicting the RLFS sequences within the proximal gene regions and in gene body at accuracy 90-92\%. Mapping RLFS data, you could increase power and the specificity of the gene models. This analysis could provide the links of the gene models with key regulatory signals related to initiation of transcription, polymerase pausing sites, alternative starts and splice variances, open chromatin regions, disease critical regions etc. All these genome signals are strongly associated with RLFS locations [Wongsurawat et al., NAR, 2012; Jenjaroenpun et al., NAR, 20,015, Ginno et al., Genome Res., 2013, Sanz et al., Molecular Cell, 2016]. The RLFS analysis may make this study more interesting, novel and biologically important.
Author's response: This is an excellent suggestion. We used QmRRFS to find R-loop forming sequences (RLFS) in the region [ATG-2000, ATG + 40] of each gene [153156]. We found that the region immediately upstream from ATG, [ATG-200, ATG] is significantly enriched for RLFS (p-value $\sim 0.0$ ). However, the study of R-loops, which are essential for transcriptional processes, is not part of the present study that focuses on the coding regions, and will be part of the next study. Also, the oil palm genome currently does not have a collection of fulllength $c D N A$ sequences. Once we are able to predict the oil palm TSS accurately, we will analyze CG skews, Rloops and other features. These analyses will be presented in a separate manuscript once the analysis is complete.

11) p. 11 Gene ontology analysis shows that many of the GC3-rich genes are stress-related, while many of the GC3-poor genes have housekeeping functions (see GO annotation in Additional file 2: Table S2). However, Table 2 shows more diverse (and actually interesting) results, which also suggest a weakness of authors' statement. Indeed, sorting out the GO categories in Additional file 2: Table S2 by the score S = (CG3-rich CG3-poor)/(CG3-rich + CG-poor) at smallest cut-off value of the score equals $|0.2|$, we observed, that 10 most strong terms (oxygen binding, structural molecule activity, secondary metabolic process, translation, sequence-specific DNA binding transcription factor, response to abiotic stimulus, cell growth, response to endogenous stimulus (last ranked term)) are following the condition $\mathrm{S}>0.2$ (CG3-rich). Furthermore, the $17 \mathrm{GO}$ terms (regulation of gene expression and epigenetic, motor activity, RNA binding, nucleotide binding, nuclease activity, lipid binding, kinase activity, nucleic acid binding, chromatin binding, translation factor activity, nucleic acid binding, signal transducer activity, protein metabolic process, catabolic process, hydrolase activity, embryo development, cell cycle, response to extracellular stimulus (last ranked term)) are following the condition $\mathrm{S}<-0.2$ (CG3-poor). I propose that the more balanced and complete analysis, interpretation and discussion of the GO enrichment data analysis will be carried out.

Author's response: We have calculated the enrichment statistics:(\#GC3-rich-\#GC3-poor)/Total number of genes, (\#GC3-rich-\#GC3-poor)/(\#GC3rich + \#GC3-poor), and also computed the chi-squared statistics. The results are shown in the GO enrichment table in Additional file 1.

12) Additional file 2: Table S8 Could you please explain and discuss the observed differences between percentage intronless (PI) genes in GC3 -rich genes belonging to the same GO branch "growth" (PI $=19 \%$ ), "cell growth" (PI $=13 \%)$, "cell cycles" $(\mathrm{PI}=6)$ Table 8)? How many of the "cell cycle" genes are included in "growth" and "cell growth" categories? How many of the "cell cycle genes" are unique? 
Author's response: There are no genes that belong to all three categories ("growth", "cell growth", and "cell cycle"). However, there are genes in the intersection of two categories. The numbers of annotated genes that fall into the three categories are as follows:

\begin{tabular}{|l|l|l|l|}
\hline & growth & cell growth & cell cycle \\
\hline Growth & 95 & & \\
\hline cell growth & 11 & 374 & \\
\hline cell cycle & 8 & 27 & 331 \\
\hline
\end{tabular}

The annotations of the INTRONLESS genes are listed below:

\begin{tabular}{|l|l|l|l|}
\hline & growth & cell growth & cell cycle \\
\hline growth & 16 & & \\
\hline cell growth & 0 & 43 & \\
\hline cell cycle & 1 & 2 & 19 \\
\hline
\end{tabular}

13) Intronless genes analysis It may be important and interesting to carry out meta-gene analysis providing the density function of GC-skew and RLFS sequence occurrences (count of the number of the sequences in a given nucleotide location) within TSS vicinity for the intron-less genes and the genes having multiple introns. It may provide new knowledge about structural and regulatory roles of the RLFS and GC-skew sequences in the intronless genes and the multi-exon genes in the oil palm genome.

Author's response: This analysis will be conducted in our next paper dedicated to TSS prediction and analysis of regulatory sequences.

\section{Additional files}

Additional file 1: Includes information of oil palm RNA-seq data, annotation of IG, R genes and FAB genes, GO and GC3. (XLSX $8028 \mathrm{~kb}$ )

Additional file 2: Supplementary Tables. (DOCX 44 kb)

Additional file 3: Supplementary Figures. (DOCX $4776 \mathrm{~kb}$ )

Additional file 4: Additional file 4 provides screenshots of PalmXplore. (DOCX 962 kb)

\section{Abbreviations}

ACCase: Acetyl-CoA carboxylase; ACP: Acyl carrier protein; Avr: Avirulence; CC: Coiled-coil; CDS: Coding sequence; CNL: CC-NBS-LRR; FA: Fatty acid; FAB2: Stearoyl-ACP desaturase; FABF: $\beta$-ketoacyl-ACP synthase II; FAD2: Oleoyl-phosphatidylcholine desaturase; FAD3: Linoleoylphosphatidylcholine desaturase; FATA: Oleoyl-ACP thioesterase; FATB: AcylACP thioesterase; GO: Gene ontology; IG: Intronless gene; LRR: Leucine-rich repeat; NBS: Nucleotide binding site; R: Resistance; STK: Serine/threonine protein kinase; TNL: Toll/interleukin-1 NBS-LRR

\section{Acknowledgements}

We thank Orion Genomics LLC for their assistance and advice in data analysis. Special thanks to the Breeding and Tissue Culture Unit for the supply of palms and RNA extraction for sequencing. We also extend our appreciation to the Director General of MPOB, Dr. Ahmad Kushairi Din, for his support and encouragement throughout the project.

\section{Funding}

This work was supported by the Malaysian Palm Oil Board. Dr. Tatiana Tatarinova, Martin Triska, and Petr Ponomarenko were supported by National Science Foundation Awards \#1456634 and \#1622840.

Availability of data and materials

As part of the Malaysian Oil Palm Genome Program (MyOPGP), and to support post-genomics efforts, we developed the palmXplore system (http://palmxplore.mpob.gov.my), a public archive for oil palm (Elaeis guineensis) gene models hosted by MPOB. The collection includes 26,059 representative gene models and annotation information from different annotation methods: Enzyme Code (KEGG), Gene Ontology (Blast2GO) and PFAM. The gene models are downloadable from http:/genomsawit.mpob.gov.my. The sequencing data can be accessed at the BioProject of the National Center for Biotechnology Information (NCBI) with accession ID PRJNA345530.

\section{Permissions}

The data collection was conducted in accordance with the Malaysian Oil Palm Board's rules and regulations. We have received the appropriate permissions from the Malaysian Oil Palm Board to conduct the described study.

\section{Authors' contributions}

All the authors performed bioinformatics analysis and interpreted data on specific experiments. K.L.C. and T.V.T designed the overall research, wrote the manuscript and contributed to the gene prediction. R.R. performed comparative genomics on the genes of interest. N.Am. provided valuable inputs on biosynthesis genes. N.Az. identified intronless genes. M.A.A.H. inferred data on R genes. P.P., M.T. and V.S. conducted gene prediction and locus scoring and provided significant bioinformatics support. N.S.N.M.S., J.N., M.F.R., R.S., D.M. and E.T.L.L. provided critical feedback and aided in manuscript preparation. All authors read and approved the manuscript.

Ethics approval and consent to participate Not applicable.

\section{Consent for publication}

Not applicable.

\section{Competing interests}

The authors declare that they have no competing interests.

\section{Publisher's Note}

Springer Nature remains neutral with regard to jurisdictional claims in published maps and institutional affiliations.

\section{Author details}

${ }^{1}$ Advanced Biotechnology and Breeding Centre, Malaysian Palm Oil Board, No. 6, Persiaran Institusi, Bandar Baru Bangi, 43000 Kajang, Selangor, Malaysia. ${ }^{2}$ Faculty of Science and Technology, Universiti Kebangsaan Malaysia, 43600 Bangi, Selangor, Malaysia. ${ }^{3}$ Department of Biology, University of La Verne, La Verne, California 91750, USA. ${ }^{4}$ Spatial Sciences Institute, University of Southern California, Los Angeles, CA 90089, USA. ${ }^{5}$ Genomics and Computational Biology Research Group, University of South Wales, Pontypridd CF371DL, UK. 'Children's Hospital Los Angeles, University of Southern California, Los Angeles, CA 90089, USA. ${ }^{7}$ Softberry Inc., 116 Radio Circle, Suite 400, Mount Kisco, NY 10549, USA.

Received: 27 April 2017 Accepted: 7 August 2017

Published online: 08 September 2017

\section{References}

1. Barcelos E, Rios S de A, RNV C, Lopes R, Motoike SY, Babiychuk E, et al. Oil palm natural diversity and the potential for yield improvement. Front Plant 
Sci. 2015;6:190. Available from: http://www.frontiersin.org/Plant_Genetics_ and_Genomics/10.3389/fpls.2015.00190/abstract.

2. MPOB. Malaysian oil palm statistics 2014. 34th ed. Malaysia: MPOB; 2015.

3. Jouannic S, Argout $X$, Lechauve F, Fizames $C$, Borgel A, Morcillo F, et al. Analysis of expressed sequence tags from oil palm (Elaeis Guineensis). FEBS Lett. 2005;579:2709-14.

4. Low ETL, Rosli R, Jayanthi N, Mohd-Amin AH, Azizi N, Chan KL, et al. Analyses of hypomethylated oil palm gene space. PLoS One. 2014;9:e86728.

5. Singh R, Ong-Abdullah M, Low E-TL, Manaf MAA, Rosli R, Nookiah R, et al. Oil palm genome sequence reveals divergence of interfertile species in old and new worlds. Nature. 2013;500:335-9. Available from: http://www. pubmedcentral.nih.gov/articlerender.fcgi?artid=3929164\&tool= pmcentrez\&rendertype=abstract $\backslash$ nhttp://dx.doi.org/10.1038/nature12309.

6. Jin J, Lee M, Bai B, Sun Y, Qu J, Rahmadsyah, et al. Draft genome sequence of an elite Dura palm and whole-genome patterns of DNA variation in oil palm. DNA Res Int J Rapid Publ Reports Genes genomes. 2016;0:1-7.

7. Singh R, Low E-TL, Ooi LC-L, Ong-Abdullah M, Ting N-C, Nagappan J, et al. The oil palm SHELL gene controls oil yield and encodes a homologue of SEEDSTICK. Nature. 2013;500:340-4. Available from: http://dx.doi.org/10. 1038/nature12356\nhttp://www.ncbi.nlm.nih.gov/pubmed/23883930.

8. Singh R, Low E-TL, Ooi LC-L, Ong-Abdullah M, Nookiah R, Ting N-C, et al, The oil palm VIRESCENS gene controls fruit colour and encodes a R2R3MYB. Nat Commun. 2014;5:4106. Available from: http://www.ncbi.nlm.nih. gov/pubmed/24978855.

9. Ong-Abdullah M, Ordway JM, Jiang N, Ooi S-E, Kok S, Sarpan N, et al. Loss of karma transposon methylation underlies the mantled somaclonal variant of oil palm. Nature. 2015;525:533-7. Available from: http://www.nature.com/ doifinder/10.1038/nature15365.

10. Burge C, Karlin S. Prediction of complete gene structures in human genomic DNA. J Mol Biol. 1997;268:78-94.

11. Brent MR. Genome annotation past, present, and future: how to define an ORF at each locus. Genome Res. 2005;15:1777-86.

12. Berendzen KW, Stüber K, Harter K, Wanke D. Cis-motifs upstream of the transcription and translation initiation sites are effectively revealed by their positional disequilibrium in eukaryote genomes using frequency distribution curves. BMC Bioinformatics. 2006;7:522.

13. Pritsker M, Liu YC, Beer MA, Tavazoie S. Whole-genome discovery of transcription factor binding sites by network-level conservation. Genome Res. 2004;14:99-108.

14. Troukhan M, Tatarinova T, Bouck J, Flavell RB, Alexandrov NN. Genome-wide discovery of cis-elements in promoter sequences using gene expression. OMICS. 2009;13:139-51. Available from: http://www.ncbi.nlm.nih.gov/ pubmed/19231992.

15. Triska M, Grocutt D, Southern J, Murphy DJ, Tatarinova T. CisExpress: Motif detection in DNA sequences. Bioinformatics. 2013;29:2203-5.

16. Tatarinova TV, Alexandrov NN, Bouck JB, Feldmann KA. GC3 biology in corn, rice, sorghum and other grasses. BMC Genomics. 2010;11:308.

17. Chan K-L, Rosli R, Tatarinova T, Hogan M, Firdaus-Raih M, Low E-TL. Seqping: gene prediction pipeline for plant genomes using self-trained gene models and Transcriptomic data. BMC Bioinformatics. 2017;18:29.

18. Solovyev V, Kosarev P, Seledsov I, Vorobyev D. Automatic annotation of eukaryotic genes, pseudogenes and promoters. Genome Biol. 2006;7(Suppl 1):S10.1-12.

19. Bourgis F, Kilaru A, Cao X, Ngando-Ebongue G-F, Drira N, Ohlrogge JB, et al. Comparative transcriptome and metabolite analysis of oil palm and date palm mesocarp that differ dramatically in carbon partitioning. Proc Natl Acad Sci U S A. 2011;108:12527-32.

20. Tranbarger TJ, Dussert S, Joët T, Argout X, Summo M, Champion A, et al. Regulatory mechanisms underlying oil palm fruit mesocarp maturation, ripening, and functional specialization in lipid and carotenoid metabolism. Plant Physiol. 2011;156:564-84.

21. Shearman JR, Jantasuriyarat C, Sangsrakru D, Yoocha T, Vannavichit A, Tragoonrung S, et al. Transcriptome analysis of normal and mantled developing oil palm flower and fruit. Genomics. 2013;101:306-12.

22. Shearman JR, Jantasuriyarat C, Sangsrakru D, Yoocha T, Vannavichit A, Tangphatsornruang S, et al. Transcriptome assembly and expression data from normal and mantled oil palm fruit. Dataset Pap Biol. 2013;2013:1-7.

23. Yao H, Guo L, Fu Y, Borsuk LA, Wen TJ, Skibbe DS, et al. Evaluation of five ab initio gene prediction programs for the discovery of maize genes. Plant Mol Biol. 2005;57:445-60.

24. Salamov AA, Solovyev W. Ab initio gene finding in drosophila genomic DNA. Genome Res. 2000;10:516-22.
25. Holt C, Yandell M. MAKER2: an annotation pipeline and genome-database management tool for second-generation genome projects. BMC Bioinformatics. 2011;12:491.

26. Altschul SF, Madden TL, Schäffer AA, Zhang J, Zhang Z, Miller W, et al. Gapped BLAST and PSI-BLAST: a new generation of protein database search programs. Nucleic Acids Res. 1997;25:3389-402.

27. Fu L, Niu B, Zhu Z, Wu S, Li W. CD-HIT: accelerated for clustering the nextgeneration sequencing data. Bioinformatics. 2012;28:3150-2.

28. Ouyang S, Buell CR. The TIGR plant repeat databases: a collective resource for the identification of repetitive sequences in plants. Nucleic Acids Res. 2004;32:D360-3.

29. Jurka J, Kapitonov W, Pavlicek A, Klonowski P, Kohany O, Walichiewicz J. Repbase update, a database of eukaryotic repetitive elements. Cytogenet. Genome Res. 2005;110:462-7.

30. Llorens C, Futami R, Covelli L, Domínguez-Escribá L, Viu JM, Tamarit D, et al. The gypsy database (GyDB) of mobile genetic elements: release 2.0. Nucleic Acids Res. 2011;39:D70-4. Available from: http://www.pubmedcentral.nih. gov/articlerender.fcgi?artid=3013669\&tool=pmcentrez\&rendertype=abstract.

31. Majoros WH, Pertea M, Salzberg SL. TigrScan and GlimmerHMM: two open source ab initio eukaryotic gene-finders. Bioinformatics. 2004;20:2878-9.

32. Allen JE, Majoros WH, Pertea M, Salzberg SL. JIGSAW, GeneZilla, and GlimmerHMM: puzzling out the features of human genes in the ENCODE regions. Genome Biol. 2006;7(Suppl 1):S9.1-13.

33. Stanke M, Diekhans M, Baertsch R, Haussler D. Using native and syntenically mapped CDNA alignments to improve de novo gene finding. Bioinformatics. 2008;24:637-44.

34. Korf I. Gene finding in novel genomes. BMC Bioinformatics. 2004;5:59.

35. Pruitt KD, Tatusova T, Maglott DR. NCBI reference sequences (RefSeq): a curated non-redundant sequence database of genomes, transcripts and proteins. Nucleic Acids Res. 2007;35(Database issue):D61-5.

36. Sonnhammer ELL, Eddy SR, Birney E, Bateman A, Durbin R. Pfam: multiple sequence alignments and HMM-profiles of protein domains. Nucleic Acids Res. 1998:26:320-2

37. Finn RD, Bateman A, Clements J, Coggill P, Eberhardt RY, Eddy SR, et al. Pfam: the protein families database. Nucleic Acids Res. 2014;42(Database issue):D222-30.

38. Johnson LS, Eddy SR, Portugaly E. Hidden Markov model speed heuristic and iterative HMM search procedure. BMC Bioinformatics. 2010;11:431.

39. Mistry J, Finn RD, Eddy SR, Bateman A, Punta M. Challenges in homology search: HMMER3 and convergent evolution of coiled-coil regions. Nucleic Acids Res. 2013;41:e121.

40. Kawahara Y, de la Bastide M, Hamilton JP, Kanamori H, McCombie WR, Ouyang S, et al. Improvement of the Oryza Sativa Nipponbare reference genome using next generation sequence and optical map data. Rice (N Y). 2013;6:4. Available from: http://www.ncbi.nIm.nih.gov/pubmed/24280374.

41. Berardini TZ, Reiser L, Li D, Mezheritsky Y, Muller R, Strait E, et al. The arabidopsis information resource: making and mining the "gold standard" annotated reference plant genome. Genesis. 2015;53:474-85.

42. Goodstein DM, Shu S, Howson R, Neupane R, Hayes RD, Fazo J, et al. Phytozome: a comparative platform for green plant genomics. Nucleic Acids Res. 2012;40:1178-86

43. Sanseverino W, Hermoso A, D'Alessandro R, Vlasova A, Andolfo G, Frusciante L, et al. PRGdb 2.0: towards a community-based database model for the analysis of R-genes in plants. Nucleic Acids Res. 2013;41(Database issue):D1 167-71.

44. Krogh A, Larsson B, von Heijne G, Sonnhammer EL. Predicting transmembrane protein topology with a hidden Markov model: application to complete genomes. J Mol Biol. 2001;305:567-80.

45. Barbosa-da-Silva A, Wanderley-Nogueira AC, Silva RRM, Berlarmino LC, Soares-Cavalcanti NM, Benko-Iseppon AM. In silico of resistance (R) genes in eucalyptus transcriptome. Genet Mol Biol. 2005;28:562-74.

46. Martin GB, Bogdanove AJ, Sessa G. Understanding the functions of plant disease resistance proteins. Annu Rev Plant Biol. 2003;54:23-61. Available from: http.// www.annualreviews.org/doi/abs/10.1146/annurev.arplant.54.031902.135035.

47. Peraza-Echeverria S, James-Kay A, Canto-Canché B, Castillo-Castro E. Structural and phylogenetic analysis of Pto-type disease resistance gene candidates in banana. Mol Gen Genomics. 2007;278:443-53. Available from: http://link.springer.com/10.1007/s00438-007-0262-9.

48. Song WY, Wang GL, Chen LL, Kim HS, Pi LY, Holsten T, et al. A receptor kinase-like protein encoded by the rice disease resistance gene, Xa21. Science. 1995;270:1804-6.

49. Yun C. Classification and function of plant disease resistance genes. Plant Pathol J. 1999;15:105-11. 
50. Thompson JD, Higgins DG, Gibson TJ. CLUSTAL W: improving the sensitivity of progressive multiple sequence. Nucleic Acids Res. 1994;22:4673-80.

51. Tamura K, Stecher G, Peterson D, Filipski A, Kumar S. MEGA6: molecular evolutionary genetics analysis version 6.0. Mol. Biol. Evolution. 2013;30:2725-9.

52. Yang S, Zhang X, Yue JX, Tian D, Chen JQ. Recent duplications dominate NBS-encoding gene expansion in two woody species. Mol Gen Genomics. 2008;280:187-98.

53. Meyers BC, Kozik A, Griego A, Kuang H, Michelmore RW. Genome-wide analysis of NBS-LRR-encoding genes in Arabidopsis. Plant Cell. 2003;15:809-34. Available from: https://www.ncbi.nlm.nih.gov/pubmed/12671079.

54. Kanehisa M, Goto S. KEGG: Kyoto encyclopedia of genes and genomes. Nucleic Acids Res. 2000;28:27-30. Available from: https://www.ncbi.nlm.nih. gov/pmc/articles/PMC102409/.

55. Okuley J, Lightner J, Feldmann K, Yadav N, Lark E, Browse J. Arabidopsis FAD2 gene encodes the enzyme that is essential for polyunsaturated lipid synthesis. Plant Cell. 1994;6:147-58. Available from: http://www.plantcell.org/ content/6/1/147.

56. Lin X, Kaul S, Rounsley S, Shea TP, Benito MI, Town CD, et al. Sequence and analysis of chromosome 2 of the plant Arabidopsis Thaliana. Nature. 1999; 402:761-8.

57. Tilton GB, Shockey JM, Browse J. Biochemical and molecular characterization of $\mathrm{ACH} 2$, an Acyl-CoA Thioesterase from Arabidopsis Thaliana. J Biol Chem. 2004;279:7487-94.

58. Jha SS, Jha JK, Chattopadhyaya B, Basu A, Sen SK, Maiti MK. Cloning and characterization of CDNAs encoding for long-chain saturated acyl-ACP thioesterases from the developing seeds of Brassica Juncea. Plant Physiol Biochem. 2010;48:476-80.

59. Slater GSC, Birney E. Automated generation of heuristics for biological sequence comparison. BMC Bioinformatics. 2005;6:31. Available from: http://www.biomedcentral.com/1471-2105/6/31

60. Quevillon E, Silventoinen V, Pillai S, Harte N, Mulder N, Apweiler R, et al. InterProScan: protein domains identifier. Nucleic Acids Res. 2005:33:116-20.

61. Sonnhammer ELL, Eddy SR, Durbin R. Pfam: a comprehensive database of protein domain families based on seed alignments. Proteins Struct Funct Genet. 1997;28:405-20.

62. Benson BK, Meades G, Grove A, Waldrop GL. DNA inhibits catalysis by the carboxyltransferase subunit of acetyl-CoA carboxylase: implications for active site communication. Protein Sci. 2008;17:34-42.

63. Barber MC, Price NT, Travers MT. Structure and regulation of acetyl-CoA carboxylase genes of metazoa. Biochim Biophys Acta. 2005;1733:1-28.

64. Waldrop GL, Rayment I, Holden HM. Three-dimensional structure of the biotin carboxylase subunit of acetyl-CoA carboxylase. Biochemistry. 1994;33: 10249-56.

65. Li M-J, Li A-Q, Xia H, Zhao C-Z, Li C-S, Wan S-B, et al. Cloning and sequence analysis of putative type II fatty acid synthase genes from Arachis Hypogaea L. J Biosci. 2009;34:227-38.

66. Haralampidis K, Milioni D. Temporal and transient expression of stearoyl-ACP carrier protein desaturase gene during olive fruit development. J Exp Bot. 1998; 49:1661-9. Available from: http://jxb.oxfordjournals.org/lookup/doi/10.1093/ jxb/49.327.1661\nhttp://jxb.oxfordjournals.org/content/49/327/1661.short.

67. Shanklin J, Whittle E, Fox BG. Eight histidine residues are catalytically essential in a membrane-associated iron enzyme, stearoyl-CoA desaturase, and are conserved in alkane hydroxylase and xylene monooxygenase. Biochemistry. 1994;33:12787-94.

68. Yuan L, Nelson BA, Caryl G. The catalytic cysteine and histidine in the plant acyl-acyl carrier protein thioesterases. J Biol Chem. 1996;271:3417-9.

69. Brenner S. The molecular evolution of genes and proteins: a tale of two serines. Nature. 1988;334:528-30.

70. Rozwarski DA, Vilchèze $C$, Sugantino M, Bittman R, Sacchettini JC. Crystal structure of the mycobacterium tuberculosis enoyl-ACP reductase, InhA, in complex with NAD+ and a C16 fatty acyl substrate. J Biol Chem. 1999;274:15582-9.

71. Smith S. The animal fatty acid synthase: one gene, one polypeptide, seven enzymes. FASEB J. 1994;8:1248-59. Available from: http://www.ncbi.nlm.nih. gov/pubmed/8001737.

72. Helmkamp GMJ, Bloch K. Beta-hydroxydecanoyl thioester dehydrase. Studies on molecular structure and active site. J Biol Chem. 1969;244:6014-22.

73. Siggaard-Andersen M. Conserved residues in condensing enzyme domains of fatty acid synthases and related sequences. Protein Seq Data Anal. 1993; 5:325-35.

74. Delcher AL, Phillippy A, Carlton J, Salzberg SL. Fast algorithms for large-scale genome alignment and comparison. Nucleic Acids Res. 2002;30:2478-83.
75. Kim D, Pertea G, Trapnell C, Pimentel H, Kelley R, Salzberg SL. TopHat2: accurate alignment of transcriptomes in the presence of insertions, deletions and gene fusions. Genome Biol. 2013;14:R36. Available from: http://genomebiology.com/2013/14/4/R36.

76. Trapnell C, Roberts A, Goff L, Pertea G, Kim D, Kelley DR, et al. Differential gene and transcript expression analysis of RNA-seq experiments with TopHat and cufflinks. Nat Protoc. 2012;7:562-78. Available from: http://dx.doi.org/10.1038/nprot.2012.016 \nhttp://www. pubmedcentral.nih.gov/articlerender.fcgi?artid=3334321\&tool= pmcentrez\&rendertype=abstract

77. Li L, Stoeckert CJ, Roos DS. OrthoMCL: identification of ortholog groups for eukaryotic genomes. Genome Res. 2003;13:2178-89.

78. Edgar R. MUSCLE: multiple sequence alignment with high accuracy and high throughput. Nucleic Acids Res. 2004;32:1792-7. Available from: http:// www.pubmedcentral.nih.gov/articlerender.fcgi?artid=390337\&tool= pmcentrez\&rendertype=abstract \nhttp://nar.oxfordjournals.org/content/32/ 5/1792.short.

79. Katoh K, Standley DM. MAFFT multiple sequence alignment software version 7 : improvements in performance and usability. Mol Biol Evol. 2013;30:772-80.

80. Mitchell A, Chang H, Daugherty L, Fraser M, Hunter S, Lopez R, et al. The InterPro protein families database : the classification resource after 15 years. Nucleic Acids Res. 2015;43:213-21.

81. Sigrist CJA, Castro E De, Cerutti L, Cuche A, Hulo N, Bridge A, et al. New and continuing developments at PROSITE. Nucleic Acids Res 2013;41:344-347.

82. Marchler-bauer A, Derbyshire MK, Gonzales NR, Lu S, Chitsaz F, Geer LY, et al. CDD: NCBI's conserved domain database. Nucleic Acids Res. 2015;43:222-6.

83. Kuraku S, Zmasek CM, Nishimura O, Katoh K. aLeaves facilitates on-demand exploration of metazoan gene family trees on MAFFT sequence alignment server with enhanced interactivity. Nucleic Acids Res. 2013;41:22-8.

84. Campbell MS, Law M, Holt C, Stein JC, Moghe GD, Hufnagel DE, et al. MAKER-P: a tool kit for the rapid creation, management, and quality control of plant genome annotations. Plant Physiol. 2014;164:513-24. Available from: http://www.pubmedcentral.nih.gov/articlerender. fcgi?artid=3912085\&tool=pmcentrez\&rendertype =abstract.

85. Liang C, Mao L, Ware D, Stein L. Evidence-based gene predictions in plant genomes. Genome Res. 2009;19:1912-23.

86. Borodovsky M, Lomsadze A. Eukaryotic gene prediction using GeneMark.HmmE and GeneMark-ES. Curr Protoc Bioinformatics. 2011; Chapter 4:Unit 4.6.1-10.

87. Besemer J, Borodovsky M. GeneMark: web software for gene finding in prokaryotes, eukaryotes and viruses. Nucleic Acids Res. 2005;33(Web Server issue):W451-4.

88. Curwen V, Eyras E, Andrews TD, Clarke L, Mongin E, Searle SMJ, et al. The Ensembl automatic gene annotation system. Genome Res. 2004;14:942-50.

89. Ouyang S, Zhu W, Hamilton J, Lin H, Campbell M, Childs K, et al. The TIGR Rice genome annotation resource: improvements and new features. Nucleic Acids Res. 2007;35(Database issue):D883-7.

90. Zhu W, Buell CR. Improvement of whole-genome annotation of cereals through comparative analyses. Genome Res. 2007;17:299-310.

91. Swarbreck D, Wilks C, Lamesch P, Berardini TZ, Garcia-Hernandez M, Foerster $\mathrm{H}$, et al. The Arabidopsis information resource (TAIR): gene structure and function annotation. Nucleic Acids Res. 2008;36(Database issue):D1009-14.

92. Shulaev V, Sargent DJ, Crowhurst RN, Mockler TC, Folkerts O, Delcher AL, et al. The genome of woodland strawberry (Fragaria Vesca). Nat Genet. 2011; 43:109-16.

93. Ge $Y$, Wang $Y$, Liu $Y$, Tan $Y$, Ren $X$, Zhang $X$, et al. Comparative genomic and transcriptomic analyses of the Fuzhuan brick tea-fermentation fungus Aspergillus cristatus. BMC Genomics. 2016;17:428. Available from: http:// bmcgenomics.biomedcentral.com/articles/10.1186/s12864-016-2637-y.

94. Calabrese S, Pérez-Tienda J, Ellerbeck M, Arnould C, Chatagnier O, Boller T, et al. GintAMT3 - a low-affinity ammonium transporter of the Arbuscular Mycorrhizal Rhizophagus Irregularis. Front Plant Sci. 2016;7:1-14. Available from: http://journal.frontiersin.org/article/10.3389/fpls.2016.00679.

95. Zhong Z, Norvienyeku J, Chen M, Bao J, Lin L, Chen L, et al. Directional selection from host plants is a major force driving host specificity in Magnaporthe species. Sci Rep. 2016;6:25591. Available from: http://www. nature.com/articles/srep25591.

96. Van Ghelder C, Esmenjaud D. TNL genes in peach: insights into the postLRR domain. BMC Genomics. 2016;17:317. Available from: http://dx.doi.org/ 10.1186/s12864-016-2635-0.

97. Simao FA, Waterhouse RM, loannidis P, Kriventseva EV, Zdobnov EM. BUSCO: assessing genome assembly and annotation completeness with single-copy orthologs. Bioinformatics. 2015;31:3210-2. 
98. Rogozin IB, Sverdlov AV, Babenko VN, Koonin EV. Analysis of evolution of exon-intron structure of eukaryotic genes. Brief Bioinform. 2005;6:118-34.

99. Schwartz $\mathrm{S}$, Meshorer E, Ast G. Chromatin organization marks exon-intron structure. Nat Struct Mol Biol. 2009;16:990-5

100. Meyer IM, Durbin R. Gene structure conservation aids similarity based gene prediction. Nucleic Acids Res. 2004;32:776-83.

101. Alexandrov NN, Brover W, Freidin S, Troukhan ME, Tatarinova TV, Zhang H, et al. Insights into corn genes derived from large-scale cDNA sequencing. Plant Mol Biol. 2009;69:179-94. Available from: http://www.pubmedcentral.nih.gov/ articlerender.fcgi?artid=2709227\&tool=pmcentrez\&rendertype=abstract.

102. Tatarinova T, Elhaik E, Pellegrini M. Cross-species analysis of genic GC3 content and DNA methylation patterns. Genome Biol Evol. 2013;5:1443-56.

103. Souvorov A, Tatusova T, Zaslasky L, Smith-White B. Glycine max and Zea Mays genome annotation with gnomon. 19th Annual International Conference on Intelligent Systems for Molecular Biology and 10th European Conference on Computational Biology. Vienna, Austria. 2011.

104. Elhaik E, Pellegrini M, Tatarinova TV. Gene expression and nucleotide composition are associated with genic methylation level in Oryza Sativa. BMC Bioinformatics. 2014;15:23.

105. Ahmad T, Sablok G, Tatarinova TV, Xu Q, Deng X-XX, Guo W-WW. Evaluation of codon biology in citrus and Poncirus Trifoliata based on genomic features and frame corrected expressed sequence tags. DNA Res. 2013;20: 135-50. Available from: http://www.pubmedcentral.nih.gov/articlerender. fcgi?artid=3628444\&tool=pmcentrez\&rendertype=abstract.

106. Karlin S, Burge C. Dinucleotide relative abundance extremes: a genomic signature. Trends Genet. 1995;11:283-90.

107. Agarwal SM, Srivastava PK. Human intronless disease associated genes are slowly evolving. BMB Rep. 2009;42:356-60.

108. Grzybowska E a. Human intronless genes: functional groups, associated diseases, evolution, and mRNA processing in absence of splicing. Biochem Biophys Res Commun. 2012;424:1-6. Available from: http://dx.doi.org/10. 1016/j.bbrc.2012.06.092.

109. Ferguson A a, Jiang N. Pack-MULEs: recycling and reshaping genes through GC-biased acquisition. Mob Genet Elements. 2011;1:135-8.

110. Jain M, Khurana P, Tyagi AK, Khurana JP. Genome-wide analysis of intronless genes in rice and Arabidopsis. Funct Integr Genomics. 2008;8:69-78.

111. Yan H, Jiang C, Li X, Sheng L, Dong Q, Peng X, et al. PIGD: a database for intronless genes in the Poaceae. BMC Genomics. 2014;15:832. Available from: http://www.biomedcentral.com/1471-2164/15/832

112. Yan $H$, Zhang $W$, Lin $Y$, Dong $Q$, Peng $X$, Jiang $H$, et al. Different evolutionary patterns among intronless genes in maize genome. Biochem Biophys Res Commun. 2014;449:146-50.

113. Bolshoy A, Tatarinova T. Methods of combinatorial optimization to reveal factors affecting gene length. Bioinform Biol Insights. 2012;6:317-27.

114. Tatarinova T, Salih B, Dien Bard J, Cohen I, Bolshoy A. Lengths of Orthologous prokaryotic proteins are affected by evolutionary factors. Biomed Res Int. 2015;2015:786861.

115. Kordis D. Extensive intron gain in the ancestor of placental mammals. Biol Direct. 2011;6:59. Available from: http://www.ncbi.nlm.nih.gov/pubmed/22112745.

116. Kordis D, Kokosar J. What can domesticated genes tell us about the intron gain in mammals? Int J Evol Biol. 2012;2012:278981. Available from: http:// dx.doi.org/10.1155/2012/278981 \nhttp://downloads.hindawi.com/journals/ ijeb/2012/278981.pdf.

117. Freeman BC, Beattie GA. An overview of plant defenses against pathogens and herbivores. Plant Heal Instr. 2008. Available from: http://www.apsnet. org/edcenter/intropp/topics/Pages/OverviewOfPlantDiseases.aspx.

118. de Wit PJ. How plants recognize pathogens and defend themselves. Cell Mol Life Sci. 2007;64:2726-32.

119. Katagiri F, Tsuda K. Understanding the plant immune system. Mol PlantMicrobe Interact. 2010;23:1531-6.

120. Meyers BC, Dickerman AW, Michelmore RW, Sivaramakrishnan S, Sobral BW, Young ND. Plant disease resistance genes encode members of an ancient and diverse protein family within the nucleotide binding superfamily. Plant J. 1999;20:317-32.

121. Ameline-Torregrosa C, Wang B-B, O'Bleness MS, Deshpande S, Zhu H, Roe BA, et al. Identification and characterization of NBS-LRR genes in the model plant Medicago Truncatula. Plant Physiol. 2008;146:5-21. Available from: http://www. plantphysiol.org/content/146/1/5.

122. Tarr DEK, Alexander HM. TIR-NBS-LRR genes are rare in monocots: evidence from diverse monocot orders. BMC Res Notes. 2009;2:197.
123. Pan Q, Wendel J, Fluhr R. Divergent evolution of plant NBS-LRR resistance gene homologues in dicot and cereal genomes. J Mol Evol. 2000;50:203-13.

124. Jones DA, Jones JDG. The role of Leucine-rich repeat proteins in plant Defences. Adv Bot Res. 1997;24:89-167. Available from: http://www. sciencedirect.com/science/article/pii/S0065229608600725.

125. Staskawicz BJ, Ausubel FM, Baker BJ, Ellis JG, Jones JD. Molecular genetics of plant disease resistance. Science. 1995;268:661-7.

126. Marone D, Russo MA, Laidò G, De Leonardis AM, Mastrangelo AM. Plant nucleotide binding site-leucine-rich repeat (NBS-LRR) genes: active guardians in host defense responses. Int J Mol Sci. 2013;14:7302-26.

127. Sessa G, D'Ascenzo M, Martin GB. Thr38 and Ser198 are Pto autophosphorylation sites required for the AvrPto-Pto-mediated hypersensitive response. EMBO J. 2000;19: 2257-69. Available from: http://www.pubmedcentral.nih.gov/articlerender. fcgi?artid=384356\&tool=pmcentrez\&rendertype $=$ abstract.

128. Shan L, Thara VK, Martin GB, Zhou JM, Tang X. The pseudomonas AvrPto protein is differentially recognized by tomato and tobacco and is localized to the plant plasma membrane. Plant Cell. 2000;12:2323-38.

129. Frederick RD, Thilmony RL, Sessa G, Martin GB. Recognition specificity for the bacterial Avirulence protein AvrPto is determined by Thr-204 in the activation loop of the tomato Pto Kinase. Mol Cell. 1998;2:241-5. Available from: http://www.sciencedirect.com/science/article/pii/S1097276500801343.

130. Sekhwal M, Li P, Lam I, Wang X, Cloutier S, You F. Disease resistance gene analogs (RGAs) in plants. Int J Mol Sci. 2015;16:19248-90. Available from: http://www.mdpi.com/1422-0067/16/8/19248/.

131. Jones JDG, Dangl JL. The plant immune system. Nature. 2006;444:323-9. Available from: http://www.ncbi.nlm.nih.gov/pubmed/17108957.

132. Büschges $R$, Hollricher $K$, Panstruga $R$, Simons $G$, Wolter $M$, Frijters $A$, et al. The barley Mlo gene: a novel control element of plant pathogen resistance. Cell. 1997;88:695-705.

133. Michelmore RW, Meyers BC. Clusters of resistance genes in plants evolve by divergent selection and a birth-and-death process. Genome Res. 1998;8:1113-30.

134. Gururani MA, Venkatesh J, Upadhyaya CP, Nookaraju A, Pandey SK, Park SW. Plant disease resistance genes: current status and future directions. Physiol Mol Plant Pathol. 2012;78:51-65. Available from: http://www.scopus.com/ inward/record.url?eid=2-s2.0-84862778017\&partnerlD=40\&md5= $15826554 b 204 c b b 4275 b c e c 6 a 7 f c c b a b$.

135. Sambanthamurthi R, Sundram K, Tan Y. Chemistry and biochemistry of palm oil. Prog Lipid Res. 2000;39:507-58.

136. Sambanthamurthi R, Abrizah O, Umi Salamah R. Biochemical factors that control oil composition in the oil palm. J Oil Palm Res. 1999;11:24-33.

137. Noh A, Rajanaidu N, Kushairi A, Mohd Rafil Y, Mohd Din A, Mohd Isa ZA, et al. Variability in fatty acid composition, iodine value and carotene content in the MPOB oil palm germplasm collection from Angola. J Oil Palm Res. 2002;14:18-23.

138. Mohd Din a, Rajanaidu N, Jalani B. Performance of Elaeis Oleifera from Panama, Costa Rica, Colombia and Honduras in Malaysia. J Oil Palm Res. 2000;12:71-80.

139. Sambanthamurthi R, Ohlrogge JB. Acetyl-coA carboxylase activity in the oil palm. In: Williams JP, Khan MU, Lem NW, editors. Physiol Biochem Mol Biol. Plant lipids. Dordrecht: Kluwer Academic Publishers; 1996. p. 26-28.

140. Omar WSW, Willis LB, Rha C, Sinskey AJ, Ramli US, Yunus AMM, et al. Isolation and utilization of acetyl-coa carboxylase from oil palm (elaeis guineensis) mesocarp. J Oil Palm Res. 2008;2:97-107.

141. Ramli US, Sambanthamurthi R. $\beta$-ketoacyl ACP synthase II in oil palm (Elaeis guineensis) mesocarp. In: Williams JP, Khan MU, Lem NW, editors. Physiol Biochem Mol Biol. Plant Lipids: Kluwer Academic Publishers; 1997. p. 69-71.

142. Umi Salamah R, Sambanthamurthi R, Omar AR, Parveez GKA, Manaf MAA, Abrizah $\mathrm{O}$, et al. The isolation and characterisation of oil palm (Elaeis Guineensis Jacq.) $\beta$-ketoacy-acyl carrier protein (ACP) synthase (KAS) ॥ cDNA. J Oil Palm Res. 2012;24:1480-91.

143. Zhang YM, Wang CC, Hu HH, Yang L. Cloning and expression of three fatty acid desaturase genes from cold-sensitive lima bean (Phaseolus Lunatus L.). Biotechnol Lett. 2011;33:395-401. Available from: http://www.ncbi.nlm.nih. gov/pubmed/20953666.

144. Parveez GKA, Rasid OA, Sambanthamurthi R. Genetic engineering of oil palm. In: Mohd Basri W, Choo YM, Chan KW, editors. Furth Adv Oil Palm Res; 2011. p. 141-201.

145. Siti Nor Akmar A, Cheah S-C, Aminah S, Ooi LC-L, Sambanthamurthi R, Murphy $D J$. Characterization and regulation of the oil palm (Elaeis Guineensis) stearoylACP Desaturase genes. J Oil Palm Res. 1999:Special Is:1-17.

146. Kachroo A, Shanklin J, Whittle E, Lapchyk L, Hildebrand D, Kachroo P. The Arabidopsis stearoyl-acyl carrier protein-desaturase family and the contribution of leaf isoforms to oleic acid synthesis. Plant Mol Biol. 2007;63:257-71. 
147. Kachroo P, Shanklin J, Shah J, Whittle EJ, Klessig DF. A fatty acid desaturase modulates the activation of defense signaling pathways in plants. Proc Natl Acad Sci U S A. 2001;98:9448-53. Available from: http://www. pubmedcentral.nih.gov/articlerender.fcgi?artid=55441\&tool= pmcentrez\&rendertype=abstract.

148. Abrizah O, Lazarus C, Fraser T, Stobart K. Cloning of a palmitoyl-acyl carrier protein thioesterase from oil palm. Biochem Soc Trans. 2000;28:619-22.

149. Abrizah O. Isolation and characterization of an acyl-acyl carrier protein (ACP) thioesterase from oil palm. UK: University of Bristol; 2001.

150. Voelker TA, Worrell AC, Anderson L, Bleibaum J, Fan C, Hawkins DJ, et al. Fatty acid biosynthesis redirected to medium chains in transgenic oilseed plants. Science. 1992;257:72-4.

151. Asemota O, San CT, Shah FH. Isolation of a kernel oleoyl-ACP thioesterase gene from the oil palm Elaeis Guineensis Jacq. Afr J Biotechnol. 2004;3:199-201.

152. Corley RHV, Tinker PB. The oil palm. Fourth ed. Oxford: Blackwell Science Ltd; 2003.

153. Wongsurawat $T$, Jenjaroenpun $P$, Kwoh CK, Kuznetsov V. Quantitative mode of R-loop forming structures reveals a novel level of RNA-DNA interactome complexity. Nucleic Acids Res. 2012;40:e16.

154. Jenjaroenpun P, Wongsurawat T, Yenamandra SP, Kuznetsov VA. QmRLFSfinder: a model, web server and stand-alone tool for prediction and analysis of R-loop forming sequences. Nucleic Acids Res. 2015;43:W527-34.

155. Ginno PA, Lim YW, Lott PL, Korf I, Chédin F. GC skew at the 59 and 39 ends of human genes links R-loop formation to epigenetic regulation and transcription termination. Genome Res. 2013;23:1590-600.

156. Sanz LA, Hartono SR, Lim YW, Steyaert S, Rajpurkar A, Ginno PA, et al. Prevalent, dynamic, and conserved R-loop structures associate with specific Epigenomic signatures in mammals. Mol Cell. 2016;63:167-78.

\section{Submit your next manuscript to BioMed Central and we will help you at every step:}

- We accept pre-submission inquiries

- Our selector tool helps you to find the most relevant journal

- We provide round the clock customer support

- Convenient online submission

- Thorough peer review

- Inclusion in PubMed and all major indexing services

- Maximum visibility for your research

Submit your manuscript at www.biomedcentral.com/submit 